\title{
Anotações Colaborativas como Hiperdocumentos de Primeira Classe na Web Semântica ${ }^{1}$
}

\author{
Claudia Akemi Izeki ${ }^{2}$ \\ Orientadora: \\ Maria da Graça Campos Pimentel ${ }^{3}$
}

Dissertação apresentada ao Instituto de Ciências Matemáticas e de Computação da Universidade de São Paulo, para Defesa do Mestrado, como parte dos requisitos para a obtenção do título de Mestre na Área de Ciências de Computação e Matemática Computacional.

USP - São Carlos

Setembro/2001

\footnotetext{
${ }^{1}$ Trabalho realizado com o apoio do CNPq.

${ }^{2}$ E-mail: cizeki@icmc.sc.usp.br

${ }^{3}$ E-mail: mgp@icmc.sc.usp.br
} 
Este documento foi preparado com o formatador de textos $\mathrm{AT}_{\mathrm{EX}}$. O sistema de citações de referências bibliográficas bibTEX utilizando o padrão apalike.

Todos os direitos reservados (c) Claudia Akemi Izeki 


\section{Dedicatória}

Dedico aos meus pais,

aos meus irmãos Lu, Marco, Cláudio, Mônica e Cris,

e ao meu amor Walter. 


\section{Agradecimentos}

Ao Walter pelo carinho, incentivo e apoio incondicional dedicados a mim e ao meu trabalho.

Aos meus pais e irmãos que me apoiaram em mais uma etapa da minha vida, psicologica e financeiramente.

Aos professores da graduação Rudinei e Marcelo Henriques que me incentivaram a fazer mestrado no ICMC-USP.

À minha orientadora e professora Graça Pimentel pela orientação, preocupação e incentivo dedicados durante o mestrado.

Aos colegas do Grupo Graça Pimentel e Laboratórios Intermídia e LABES: Ale, Aline, Carlos, Íris, Laércio, Mari, Otávio, Pedro, Renan, Toño, Wagner, Werley, Willie e principalmente ao Juninho, Renato e Orlando pelas valiosas ajudas ao meu trabalho.

À grande família de amigos "Miguel Petroni": Adenilso, André, Claudinho, Dani, Débora, Enzo, Ged, Igor, Ivone, Renato Pagotto, Thaty, Will e Zé.

Aos amigos que tenho desde a graduação: Cris, Danival, Hana e Rogério.

Aos meus grandes amigos de tempos memoráveis Claudia e Marcelo.

Ao CNPq pelo auxílio financeiro. 


\section{Resumo}

Anotações têm sido associadas a documentos em todas as gerações de sistemas hipermídia. Este trabalho explora o uso de anotações como hiperdocumentos de primeira classe baseados em sua semântica. Nesse contexto, anotações são entidades próprias, na forma de hipertexto, possuindo seus próprios atributos e operações. A Web Semântica é uma extensão da Web atual na qual é dado um significado bem definido à informação, permitindo que informações sejam compreensíveis não só por humanos, mas também por computadores. Este trabalho possui como objetivo prover um serviço aberto, o GroupNote, de suporte a anotações colaborativas como hiperdocumentos de primeira classe na Web Semântica. Para prover esse serviço foram realizadas a modelagem conceitual e a definição e implementação de uma API, a API GroupNote. Como um estudo de caso do serviço GroupNote foi construída a aplicação WebNote, uma ferramenta que permite que usuários tenham seu próprio repositório de anotações na Web. 


\begin{abstract}
Annotations have been associated with documents in all the generations of hypermedia systems. This work investigates annotations as first class hyperdocuments based on their semantics: annotations are entities (with their own attributes and operations) in the hypertext form. The Semantic Web is an extension of the current Web in which a well defined meaning is given to information, allowing the information to be comprehensible not only by humans, but also by machines. This work aims at providing an open service, GroupNote, to support collaborative annotations as first class hyperdocuments in the Semantic Web. The provision of the GroupNote service demanded the conceptual modeling, the definition and implementation of its API. As a case study of the GroupNote service, the WebNote application was built as a tool that allows users to have your own repository of annotations in the Web.
\end{abstract}




\section{Sumário}

1 Introdução 1

2 Anotações em alguns Sistemas Hipermídia de Segunda Geração 3

2.1 Considerações Iniciais . . . . . . . . . . . . . . . . . . . . . . . . 3

2.2 Guide . . . . . . . . . . . . . . . . . . . . . 4

2.3 NoteCards . . . . . . . . . . . . . . . . . . . . . . . 4

2.3.1 Componentes Básicos do NoteCards . . . . . . . . . . . . . . 5

2.3.2 Exemplos de Anotações Suportadas pelo NoteCards . . . . . . . . . 5

2.4 KMS - Knowledge Management System . . . . . . . . . . . . . . . 6

2.4.1 Os Nós, as Âncoras e as Ligações . . . . . . . . . . . . . . . . . 7

2.4.2 Manipulação do Conteúdo dos Frames . . . . . . . . . . . . . . 8

2.4 .3 Anotações . . . . . . . . . . . . . . . . . . . . . . 8

2.5 Intermedia/InterNote $\ldots \ldots \ldots \ldots \ldots$

2.5.1 Warm Linking . . . . . . . . . . . . . . . . . . . . . 10

2.5.2 Criação de Anotações . . . . . . . . . . . . . . . . . . . . . . . . . . 10

2.5.3 Note Folder . . . . . . . . . . . . . . . . . . . . . . . . . 11

2.5.4 Revisão de Documentos . . . . . . . . . . . . . . . . . . . . 11 
2.6 Considerações Finais . . . . . . . . . . . . . . . . . . . . . . . . . . 12

3 Anotações na Web 14

3.1 Considerações Iniciais . . . . . . . . . . . . . . . . . . . . . . . . . 14

3.2 Submarino - um Site de Comércio Eletrônico . . . . . . . . . . . . . . . . . 14

3.3 WebCT - uma Ferramenta para Criação de Cursos On-line . . . . . . . . . 15

3.4 AulaNet - um Ambiente para a Criação, Participação e Administração de Cursos On-line . . . . . . . . . . . . . . . . . . . 16

3.5 IJHCS - um Site de Publicação de Artigos Científicos . . . . . . . . . . . . 17

3.6 eClass - um Sistema de Captura e Acesso de Experiências "Ao vivo" . . . . 18

3.7 CoWeb - uma Ferramenta para Autoria Colaborativa de Páginas Web . . . 18

3.8 NotePals - uma Aplicação que Executa sobre Assistentes Digitais Pessoais 19

3.9 Annotea - um Sistema de Anotação Aberto do W3C . . . . . . . . . . . . 20

3.10 CoNote - um Sistema Colaborativo de Anotações . . . . . . . . . . . . . . 22

3.11 ComMentor - um Sistema de Anotação Implementado como um Browser

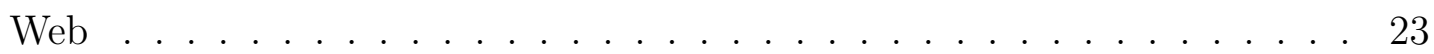

3.12 CritLink - um Sistema de Anotação Implementado como um Mediador . 23

3.13 HyperWave - um Ambiente de Gerenciamento Avançado de Documentos . 25

3.14 Considerações Finais . . . . . . . . . . . . . . . . . 25

4 Resource Description Framework (RDF) 27

4.1 Considerações Iniciais . . . . . . . . . . . . . . . . . . . . . . 27

4.2 Modelo de Dados RDF . . . . . . . . . . . . . . . . . 28

4.3 Sintaxe $\mathrm{RDF} \ldots \ldots \ldots \ldots \ldots \ldots$

4.4 Esquema RDF . . . . . . . . . . . . . . . . . 34 
4.5 Considerações Finais . . . . . . . . . . . . . . . . . . . . . . 35

5 Serviço GroupNote: Modelagem e Implementação $\quad 37$

5.1 Considerações Iniciais . . . . . . . . . . . . . . . . . . . . . . 37

5.2 Requisitos . . . . . . . . . . . . . . . . . . 38

5.3 Modelagem Conceitual . . . . . . . . . . . . . . . . . . . 39

5.4 Modelagem de Anotações e Pastas de Anotações na Web Semântica . . . . 41

5.4.1 Modelagem RDF de Anotação . . . . . . . . . . . . . . . . . 41

5.4.2 Modelagem RDF de Pasta de Anotações . . . . . . . . . . . . . . . 43

5.4.3 Uma Porção do Esquema RDF dos Recursos Anotação e Pasta de Anotações . . . . . . . . . . . . . . . . . . . . 45

5.5 API GroupNote . . . . . . . . . . . . . . . . . 47

5.6 Considerações Finais . . . . . . . . . . . . . . . . . . . . . . 48

6 WebNote: Um Estudo de Caso 49

6.1 Considerações Iniciais . . . . . . . . . . . . . . . . . . . . . . . . . . . 49

6.2 Suporte da API GroupNote . . . . . . . . . . . . . . . . . 50

6.3 Visão Geral do WebNote . . . . . . . . . . . . . . . . . . . . . . . 51

6.4 Pastas - Hierarquia e Operações . . . . . . . . . . . . . . . . . 52

6.5 Operações sobre Anotações . . . . . . . . . . . . . . . . . . . . 54

6.6 Mudança de Grupo . . . . . . . . . . . . . . . . . . . . . 57

6.7 Considerações Finais . . . . . . . . . . . . . . . . . . . . . 57

7 Conclusões e Trabalhos Futuros $\quad 59$

7.1 Contribuições . . . . . . . . . . . . . . . . . . . 60 
7.2 Trabalhos Futuros . . . . . . . . . . . . . . . . 60

7.3 Considerações Finais . . . . . . . . . . . . . . . . . . . . 61

$\begin{array}{lll}\text { A WebDAV - suporte ao controle de concorrência } & 67\end{array}$ 


\section{Lista de Figuras}

2.1 Exemplo de um frame KMS [Yoder et al., 1989] . . . . . . . . . . . . . 7

2.2 Mecanismo warm linking do sistema Intermedia [T. Catlin, 1989]. . . . . . 10

2.3 Janela Note do Intermedia[T. Catlin, 1989]. . . . . . . . . . . . . . . 11

3.1 Anotação suportada pelo site de comércio eletrônico Submarino. . . . . . . 15

3.2 As duas interfaces de visualização de comentários do IJHCS. . . . . . . . . 17

3.3 Anotação do professor no eClass. . . . . . . . . . . . . . . . . . . 19

3.4 Anotações colaborativas entre alunos e professores no eClass através da ferramenta colaborativa CoWeb. . . . . . . . . . . . . . 20

3.5 Anotações em documentos Web utilizando o browser e editor Amaya com o serviço de anotações Annotea. . . . . . . . . . . . . . . . . . . . . . . . . 21

3.6 Interface de anotações no CritLink. . . . . . . . . . . . . . . 24

4.1 Exemplo de um statement RDF representado por um diagrama de nós e arcos. . . . . . . . . . . . . . . . . . . . 29

5.1 Modelo conceitual do serviço de anotações GroupNote. . . . . . . . . . . . 39

5.2 Modelo de dados RDF de um recurso Anotação. . . . . . . . . . . . . . . . 42

5.3 Uma instância RDF de um recurso Anotação. . . . . . . . . . . . . . . . . 43

5.4 Modelo de dados RDF de um recurso Pasta. . . . . . . . . . . . . . . . . . 44 
5.5 Uma instância RDF de um recurso Pasta. . . . . . . . . . . . . . . . . 45

5.6 Uma porção do esquema RDF dos recursos Anotação e Pasta . . . . . . . . 46

6.1 A interface do WebNote é composta por três frames. . . . . . . . . . . . 52

6.2 Apresentação das pastas em hierarquia no WebNote. . . . . . . . . . . . 53

6.3 Janela com as propriedades da pasta atual no WebNote. . . . . . . . . . 54

6.4 Apresentação de alguns metadados das anotações da pasta atual no WebNote. 54

6.5 Interface de criação de anotação no WebNote. . . . . . . . . . . . . . 55

6.6 Exemplo de um documento XHTML de uma anotação. . . . . . . . . . . 56

6.7 Interface de busca de anotações no WebNote. . . . . . . . . . . . . . . . . 57

6.8 Janela para mudança de grupo no WebNote. . . . . . . . . . . . . 57 


\section{Lista de Tabelas}

4.1 As partes de um statement RDF: recurso, propriedade e valor. . . . . . . 28 


\section{Capítulo 1}

\section{Introdução}

Anotações em hiperdocumentos têm sido freqüentemente investigadas antes mesmo da criação do primeiro sistema hipermídia. Vannevar Bush em 1945 propôs uma máquina, denominada de Memex [Bush, 1945], que conteria uma grande biblioteca de informações bem como anotações pessoais e fotografias. Na década de 60, Douglas Engelbart e Ted Nelson também discutiam anotações em seus sistemas hipermídia Augment [Engelbart, 1984] e Xanadu [Nelson, 1992], respectivamente. Já nos anos 80, os sistemas hipermídia Intermedia [Yankelovich et al., 1988], NoteCards [Halasz et al., 1987], KMS [Akscyn et al., 1987] e Guide [Brown, 1987], entre outros, também possibilitavam aos leitores a inserção de anotações nos hiperdocumentos por eles manipulados. Trabalho recente tem envolvido suporte a anotações sobre documentos em formato eletrônico usando computadores baseados em caneta [Schilit et al., 1998], e sobre documentos Web gerados automaticamente por ambientes de computação ubíqüa [Pimentel et al., 2001]. No trabalho de [Adriano et al., 1999] são discutidas mudanças de paradigmas de interação em ambientes de anotação.

Este trabalho explora o uso de anotações como hiperdocumentos de primeira classe baseados em sua semântica. Nesse contexto, anotações são entidades próprias, na forma de hipertexto, que possuem seus próprios atributos e operações.

A Web Semântica é uma extensão da Web atual na qual é dado um significado bem definido à informação, ou seja, são atribuídos metadados à informação, permitindo que informações sejam compreensíveis não só por humanos, mas também por computadores [Berners-Lee et al., 2001, W3C, 2001c]. Com o intuito de tornar isso possível, o World Wide Web Consortium (W3C) propôs o RDF (Resource Descrition Framework), que é um 
mecanismo para a descrição de metadados. Devido à participação de grandes organizações como Netscape, Microsoft, IBM e Nokia na Equipe de Trabalho RDF do W3C, esperase um desenvolvimento em larga escala de ferramentas que processem RDF, levando à adoção em larga escala do RDF na Web.

Este trabalho possui como objetivo prover um serviço aberto de suporte a anotações colaborativas como hiperdocumentos de primeira classe na Web Semântica, de forma a ser utilizado por várias aplicações e ser extensível. Para prover esse serviço, denominado GroupNote, as seguintes atividades foram realizadas:

- Levantamento de requisitos através, principalmente, do estudo de alguns sistemas hipermídia de segunda geração e do estado da arte de anotações na Web;

- Modelagem conceitual do serviço;

- Modelagem RDF de anotações e pastas de anotações;

- Definição e implementação de uma API (Application Programming Interface) para o serviço; e

- Validação da API implementada através da implementação de uma aplicação que suporta anotações individuais e de grupos na Web, na qual cada usuário possui seu próprio repositório de anotações na Web, independentemente de qualquer documento sendo anotado.

Este trabalho encontra-se dividido da seguinte forma: no Capítulo 2 são discutidas as características das anotações suportadas por alguns sistemas hipermídia de segunda geração. No Capítulo 3 é apresentado o estado da arte de anotações na Web através do estudo de diversas aplicações que a Web abrange. No Capítulo 4 são introduzidos os principais componentes do RDF, que são os instrumentos para modelar os metadados de anotações. No Capítulo 5 é definido o serviço de anotações GroupNote com seus correspondentes levantamento de requisitos, modelagem conceitual, modelagem RDF de anotações e pastas, e definição e implementação da API GroupNote. No Capítulo 6 é apresentada a aplicação WebNote, implementada utilizando-se a API GroupNote. Finalmente, no Capítulo 7 são apresentadas as conclusões e trabalhos futuros. 


\section{Capítulo 2}

\section{Anotações em alguns Sistemas Hipermídia de Segunda Geração}

\subsection{Considerações Iniciais}

O objetivo deste capítulo é levantar requisitos para o serviço GroupNote através do estudo de alguns sistemas hipermídia de segunda geração que suportam anotações. Como esses sistemas foram construídos com finalidades distintas, os mecanismos de anotações suportados por eles também diferem entre si, gerando mecanismos de diferentes complexidades.

Para melhor entendimento, os sistemas hipermídia estudados são apresentados em ordem de complexidade de suporte a anotações e segundo características de anotações como: finalidade, concorrência, permissões de acesso e interfaces de edição e de apresentação da anotação.

Este capítulo encontra-se organizado da seguinte forma: nas Seções 2.2, 2.3, 2.4 e 2.5 são apresentados os sistemas Guide, NoteCards, KMS e Intermedia, respectivamente. Por último, na Seção 2.6 são apresentadas as considerações finais deste capítulo apresentando alguns requisitos para o serviço GroupNote. 


\subsection{Guide}

Guide [Brown, 1987] foi um sistema que originou de um projeto de pesquisa na University of Kent at Catenbury em 1982 e seu objetivo era apresentar documentos em telas de computadores. Em 1984, o Office Workstations Ltda implementou o Guide como um produto comercial para computadores pessoais.

Guide suporta texto e gráficos utilizando diferentes tipos de âncoras para a navegação dos hiperdocumentos e visualização de anotações feitas pelo autor do documento. As âncoras diferem-se entre si pelas diferentes fontes e formas que o cursor adquire ao ser posicionado sobre as âncoras. Geralmente são utilizadas três tipos de âncoras no sistema Guide:

- Substituição: é o mecanismo mais importante para explorar hiperdocumentos. Quando o usuário seleciona a âncora, o cursor adquire a forma de um 'X' dentro de um círculo e a âncora é substituída in-line pelo material ligado a ela. As âncoras são exibidas em fonte bold e a substituição de uma âncora pode conter outras âncoras. Com isso, o leitor pode explorar um documento expandindo sucessivamente as âncoras até alcançar o nível de detalhe que deseja. O leitor também pode voltar ao nível de detalhe anterior posicionando o cursor, que adquire a forma de um quadrado, em alguma parte do texto expandido.

- Anotação: mostra o texto de destino em uma janela separada e é geralmente usada para anotações do tipo rodapé. A janela é apresentada enquanto o usuário aperta o botão do mouse sobre a âncora. Nessa operação o cursor adquire a forma de um asterisco.

- Referência: é usado para "pular" para um ponto diferente do documento ou para um outro documento. Nessa operação o cursor toma a forma de uma flecha que aponta para a direita.

\section{$2.3 \quad$ NoteCards}

NoteCards [Halasz, 1988, Halasz et al., 1987, Trigg and Irish, 1987] foi um sistema hipermídia projetado para ajudar as pessoas a trabalhar com idéias. Foi desenvolvido por Randall Trigg, Thomas Moran, e Frank Halasz no Xerox PARC em 1985. 
NoteCards é baseado em uma rede de cartões de nota (notecards) interconectados por ligações tipadas ${ }^{1}$. Essa rede permite que o usuário represente suas idéias de forma a estarem relacionadas.

\subsubsection{Componentes Básicos do NoteCards}

NoteCards é composto de 4 elementos básicos: notecards, ligações, browsers e filebox. Um notecard (ou simplesmente cartão) é uma analogia eletrônica de um cartão de papel de 3 x 5 polegadas utilizado geralmente para anotações. Cada cartão possui um título e uma quantidade qualquer de informações editáveis, como texto e gráfico. Um editor apropriado para cada tipo de cartão (de texto, de gráfico, etc.) é ativado quando um cartão é exibido na tela. Múltiplos cartões podem ser apresentados simultaneamente na tela e com tamanhos diferentes.

As ligações interconectam um cartão origem a um cartão destino. As ligações são ancoradas por um ícone em um local específico do cartão fonte, mas são ancoradas no cartão destino como um todo. Quando um ícone é selecionado com o mouse, o cartão destino é aberto.

NoteCards foi um dos sistemas hipermídia pioneiros a utilizar fortemente um browser gráfico implementado como um cartão que mostra um diagrama estrutural de uma rede de cartões, na qual os nós da rede são os ícones dos cartões, e as arestas são linhas que representam as ligações entre os cartões. O usuário pode requisitar ao sistema a criação de um browser sobre uma sub-rede de nós e navegar entre eles.

Fileboxes são cartões especializados que podem ser usados para organizar ou categorizar grandes coleções de cartões. O NoteCards requer que todo cartão (incluindo fileboxes) deve ser arquivado em um ou mais fileboxes, obrigando os usuários a utilizarem uma estrutura hierárquica para armazenamento e para propósitos de busca.

\subsubsection{Exemplos de Anotações Suportadas pelo NoteCards}

Anotações no sistema NoteCards são suportadas pelos componentes básicos apresentados anteriormente. Em [Trigg and Irish, 1987] são apresentadas as várias atividades de escrita

\footnotetext{
${ }^{1} \mathrm{O}$ tipo de uma ligação é um rótulo escolhido pelo usuário que especifica a natureza do relacionamento sendo apresentado.
} 
que 20 pesquisadores do Xerox realizaram com o NoteCards, como tomar notas e preparar documentos. Na atividade de tomar notas foi verificado como os usuários organizam e armazenam suas anotações individuais.

No primeiro caso, um usuário utilizava um "Whiteboard" filebox correspondente a uma lousa física. Esse filebox possuía "cartões velhos e textos perdidos". Periodicamente o usuário ordenava a sua caixa, arquivando cartões e movendo textos em cartões novos ou naqueles já existentes. Essa atividade é comparada à ação de copiar notas e figuras da lousa para o papel e então apagando a lousa para recomeçar.

No segundo caso, o mesmo usuário possuía um segundo mecanismo chamado de depósito para armazenamento de anotações. O depósito era um filebox desordenado, não estruturado que continha cartões relacionados a um tópico mais geral. O usuário ocasionalmente olhava no seu depósito a anotação que poderia ser usada em sua escrita.

No terceiro caso, um outro usuário possuía um filebox de miscelânea de "pensamentos", no qual ele colocava cartões ainda não categorizados. Por exemplo, ao observar que um cartão se encaixava em seu artigo, ele o arquivava em um de seus fileboxes que compunham o esboço do artigo.

No quarto caso, um mecanismo de anotação era tomar notas de fitas de áudio. Cada fita possuía um filebox correspondente, embora vários estivessem vazios para serem preenchidos posteriormente.

No último caso, um tipo especial de anotações envolvia a articulação de pensamentos para escrever um artigo e era chamado de brainstorming. Esse esquema utilizava um browser NoteCard para criar facilmente cartões que tinham frases curtas como títulos. Esses títulos podiam ser arranjados espacialmente para indicar relacionamentos entre eles.

\subsection{KMS - Knowledge Management System}

KMS [Yoder et al., 1989, Akscyn et al., 1987] foi um sistema hipermídia de uso geral desenvolvido pela Knowledge Systems em 1983 para suportar a colaboração em grandes organizações para várias aplicações. Essas aplicações são variadas, como publicação eletrônica, gerenciamento de projeto e documentação on-line. O KMS foi o sucessor comercial do sistema ZOG desenvolvido na Carnegie Mellon University desde 1972. 


\subsubsection{Os Nós, as Âncoras e as Ligações}

O nó do sistema KMS é chamado de frame e corresponde a um espaço de trabalho do tamanho da tela do computador. Cada frame possui tamanho fixo e pode conter qualquer combinação de ítens de texto, gráfico e imagem. O KMS permite que os nós possam estar espalhados em uma rede de estações de trabalho. O KMS implementa esquemas de proteção ao nível de frames. Cada frame possui seu proprietário e este pode proteger o frame de modo que outros usuários sejam impedidos de acessá-lo ou podendo fazê-lo apenas para leitura.

O usuário possui a liberdade de estruturar seus frames da maneira que desejar. Entretanto, os autores sugerem que a organização hierárquica traz uma série de vantagens, como: facilidade para um usuário se localizar nesses frames do que nos frames não hierárquicos; o sistema oferece ferramentas que trabalham sobre a hierarquia de frames, como a busca de padrões.

Na Figura 2.1 é apresentado um exemplo de frame do KMS. A âncora do KMS é um item textual em um frame. O texto do item representa a semântica da ligação e geralmente é uma única linha de texto. Existem dois tipos de ítens de ligação (ítens textuais que são ligados a outros frames): ítens de árvore, que são uma hierarquia de frames como, por exemplo, um capítulo de um livro; e ítens de anotação, ligados a comentários e referências cruzadas. Cada item individual pode ser ligado a qualquer outro frame (indicado por um círculo vazio) ou a uma ação que invoca um programa (círculo sólido pequeno).

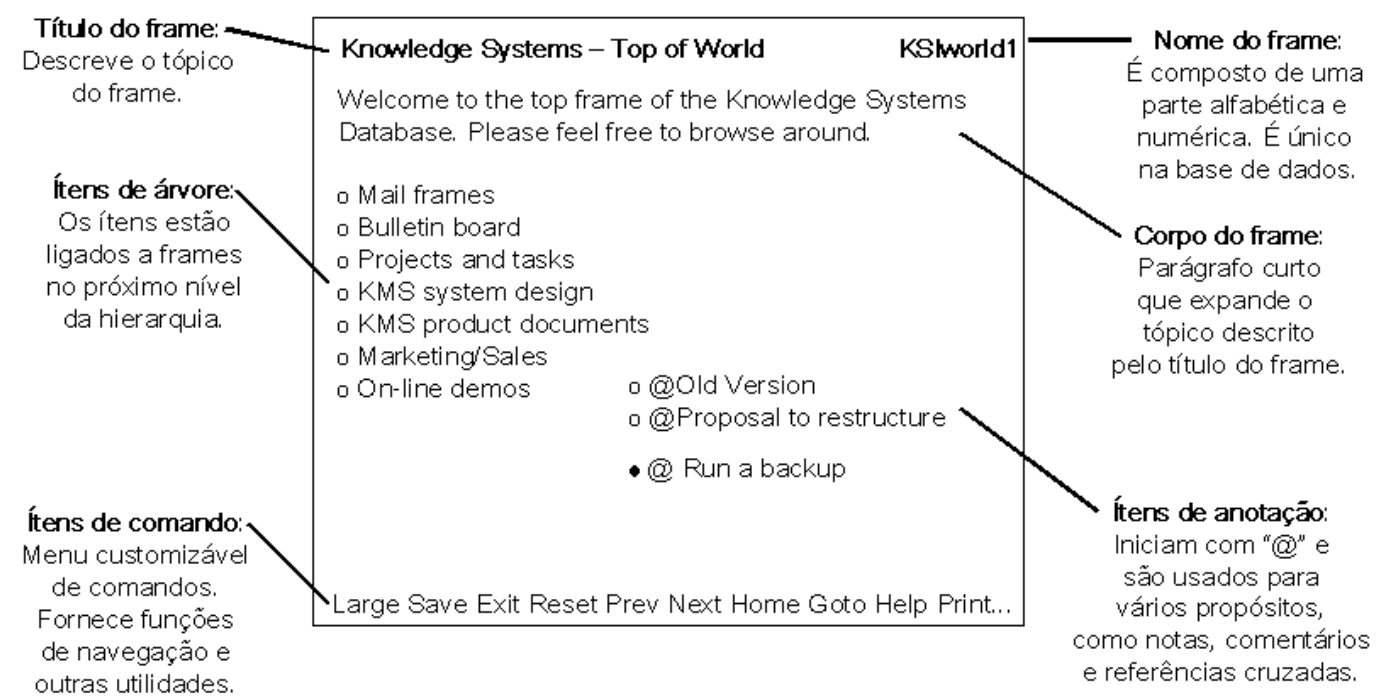

Figura 2.1: Exemplo de um frame KMS [Yoder et al., 1989]. 


\subsubsection{Manipulação do Conteúdo dos Frames}

Em qualquer momento um usuário pode manipular (criar frames, navegar entre eles, estruturar as suas informações, etc.) diretamente o conteúdo de um frame movendo o cursor do mouse sobre a tela e clicando sobre os seus botões (o KMS utiliza um mouse de 3 botões), ou digitando pelo teclado, no caso de edição.

A localização do cursor (se ele está em um espaço vazio ou dentro de um item de texto) determina que funções estão disponíveis para cada botão do mouse. Para saber quais funções estão disponíveis, as imagens do cursor incluem labels textuais. Por exemplo, se o usuário aponta o cursor do mouse em um item que não possui ligação com um frame, as funções disponíveis para cada botão do mouse são respectivamente (da esquerda para a direita): criar frame, mover item, copiar item e apagar item. Esta última função é disponível clicando os botões do meio e da direita ao mesmo tempo.

Os comandos fornecidos pelos botões do mouse também são fornecidos pelo menu localizado na porção inferior do frame. Pesquisas realizadas detectaram que utilizar as funcionalidades dos botões do mouse torna a manipulação do frame mais rápida do que a utilização do menu. Porém, o menu oferece muito mais funcionalidades do que os botões do mouse, como help, ir para o frame home e imprimir o frame atual.

Os usuários podem navegar de um frame a outro pelo menu, ou apontando o cursor do mouse em um item (que esteja ligado a qualquer frame) e clicando um dos botões do mouse. Na mesma janela o frame atual é substituído pelo posterior. O KMS não implementa browser gráfico.

O destino de uma ligação é um frame inteiro, não uma parte dele. Quando um item já foi visitado e o usuário retorna ao frame que o contém, uma marcação temporária com um asterisco é feita automaticamente para evitar a desorientação do usuário.

\subsubsection{Anotações}

Como os frames são espaços de trabalho de propósito geral, com uma variedade de usos, os usuários podem estruturá-los da forma que desejar. Para a finalidade de anotações, os usuários do KMS geralmente as utilizam para fazer comentários sobre os trabalhos dos outros e fazer rascunhos para a escrita de artigos. A seguir estão as várias maneiras de se fazer uma anotação. 
- O conteúdo da anotação é visível junto ao texto a que se refere;

- Como ítens de anotação, nos quais geralmente são inseridos comentários; e

- Como ítens de árvore.

Essas anotações podem ser tanto individuais quanto colaborativas. O autor do frame pode restringir acesso de leitura e escrita ao frame. Ou seja, ele pode permitir que leitores apenas vejam seu frame sem adicionar qualquer anotação, ou permitir que o leitor veja seu frame e adicione novos ítens de anotação sem apagar o conteúdo já existente, ou ainda proibi-lo de ver o frame.

\subsection{Intermedia/InterNote}

O Sistema Intermedia [Yankelovich et al., 1988] foi desenvolvido na Brown University no IRIS (Institute for Research in Information and Scholarship) em 1985 por uma equipe de desenvolvedores liderada por Norman K. Meyrowitz para fornecer um ambiente para ensino e pesquisa em uma universidade.

O projeto do Intermedia se baseou no fato de que, quando pessoas trabalham juntas para criar materiais, como artigos, documentos de projeto de software, e informação para usar em sala de aula, a evolução desses materiais depende do consenso de todos. Esse processo envolve não somente comentários, questionamentos e críticas aos trabalhos dos colegas, mas também a incorporação desses adendos ao material original para criar uma nova versão.

Como os grupos de usuários do Intermedia começaram a desenvolver materiais que envolviam a colaboração de todos, como livros on-line, escrita de artigos e projeto de software, houve a necessidade de fornecer ferramentas de colaboração mais eficientes. Como resultado surgiu um sistema denominado InterNote [T. Catlin, 1989].

Com o InterNote, pode-se anotar em todo tipo de documento Intermedia (texto, gráfico e figura). A anotação é feita utilizando-se o comando "Create Annotation". Os autores do documento podem utilizar o comando "Incorporate Annotation" para revisar o documento com as mudanças sugeridas da anotação. Para suportar esses dois comandos, foi feita uma extensão da ligação navegacional do Intermedia. Essa extensão foi projetada para combinar a navegação com a transferência de dados em uma única ação, denominada de warm linking. 


\subsubsection{Warm Linking}

Para transferir dados através de uma ligação, o usuário seleciona a âncora da ligação e atribui o comando Push ou Pull. O comando Push copia os conteúdos da âncora local e cola-os no outro final da ligação. O comando Pull tem o efeito oposto, copiando os conteúdos da âncora remota sobre a âncora local. Na Figura 2.2 é apresentado o mecanismo de warm linking do sistema Intermedia.

No diagrama da Figura 2.2a, o quadrado no Documento A está ligado ao círculo no Documento B. A existência da ligação é indicada pelos marcadores em cima do círculo e do quadrado. O Documento A é o documento ativo. As outras duas ilustrações mostram o que acontece se o usuário seleciona o marcador de ligação no Documento A e atribui os comandos Pull (Figura 2.2b) ou Push (Figura 2.2c).
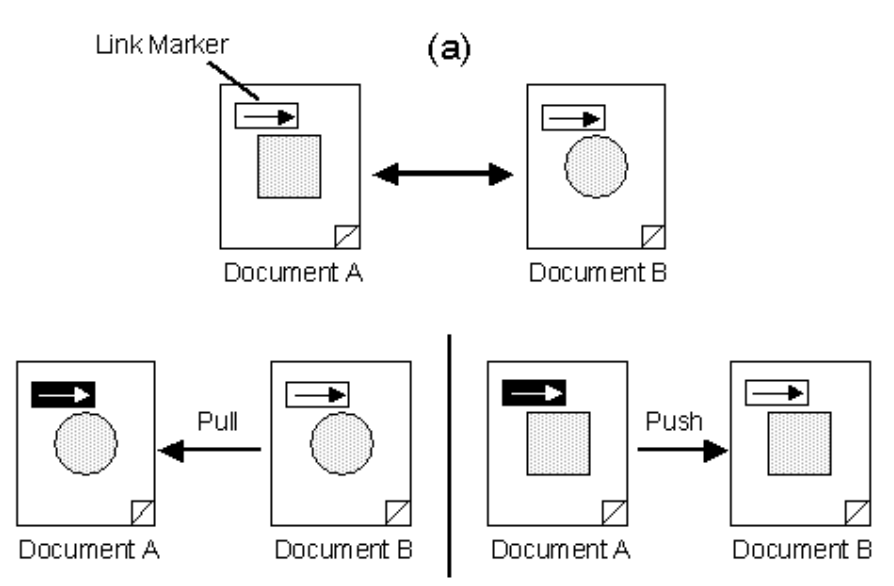

(b)

(c)

Figura 2.2: Mecanismo warm linking do sistema Intermedia [T. Catlin, 1989].

\subsubsection{Criação de Anotações}

Para criar uma anotação em documentos Intermedia, o usuário deve selecionar qualquer parte do documento e escolher o comando "Create Annotation" do menu. Com isso, abre-se uma janela chamada Note, apresentada na Figura 2.3, composta de dois frames: o Incorporation Frame, localizado na parte superior da janela e o Commentary Frame, localizado na parte inferior da janela.

Após a criação do Note, o Incorporation Frame contém inicialmente uma cópia exata do material que foi escolhido para anotar. O usuário que anota (anotador) pode editar os conteúdos do Incorporation Frame podendo incluir sugestões para a revisão do documento 
no Commentary Frame. A razão para essa estrutura é permitir que o anotador faça mudanças em uma cópia de uma seleção do draft (documento que está sendo anotado) e forneça comentário textual que possa explicar ou justificar a mudança sugerida. Vários anotadores podem adicionar anotações ao mesmo documento.

Uma anotação pode ser anotada também. Isso permite que um anotador comente sobre comentários ou revisões sugeridas por outro anotador.

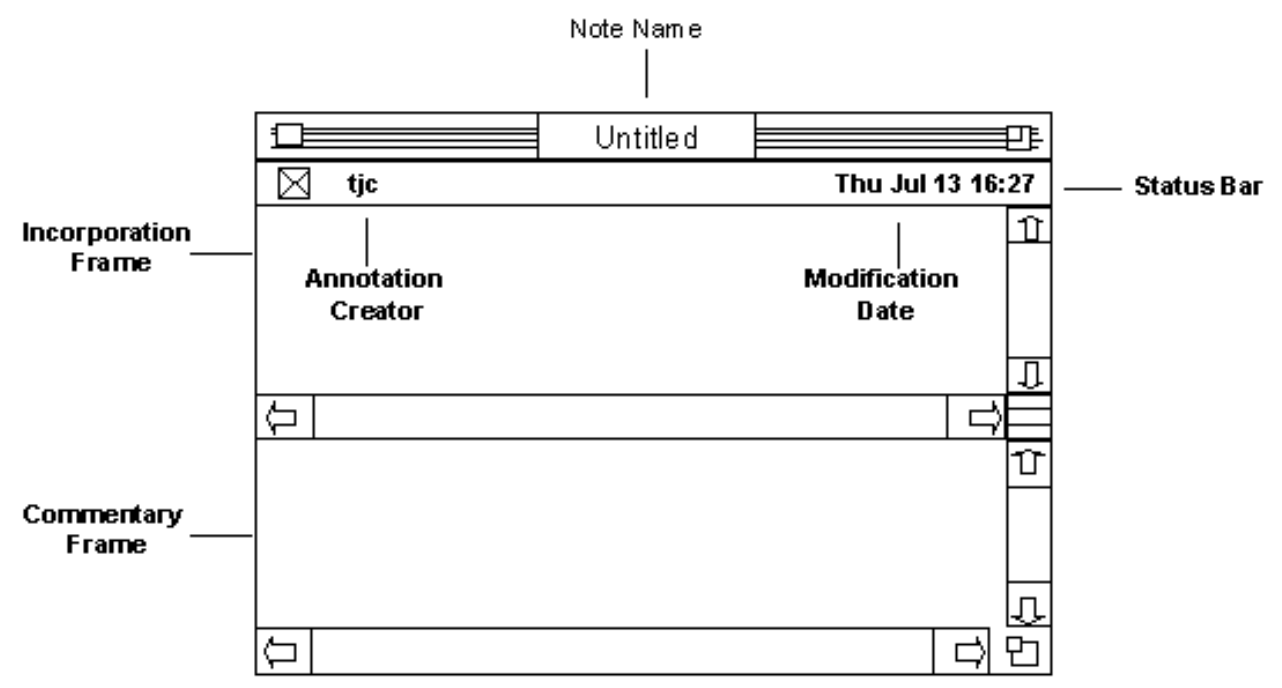

Figura 2.3: Janela Note do Intermedia[T. Catlin, 1989].

\subsubsection{Note Folder}

Todo draft possui uma pasta de anotação (Note Folder) com todas as anotações referentes a ele. As anotações de anotações também são armazenadas nesse folder. Os Note Folders são úteis para ordenar e organizar as anotações. Para visualizar as marcações de ligação que indicam que partes do documento foram anotadas, o Note Folder do documento tem que ser aberto. Ao fechar o folder, isso esconderá os marcadores de anotação. Os Notes são apresentados no folder em um formato de tabela com campos como título da anotação, data e status.

\subsubsection{Revisão de Documentos}

Se um documento foi anotado, os autores podem revisar o documento baseado nas mudanças e comentários sugeridos. Para ver as anotações, o autor deve primeiro abrir o 
folder correspondente. Os marcadores de anotação então aparecem e o autor pode seguir as ligações do documento anotado ou dar um duplo clique sobre seus nomes na tabela do folder. O autor pode ver simultaneamente o documento fonte e as anotações para determinar se as incorpora ou não ao draft. Caso o autor não esteja certo da área do documento que aquela anotação deseja substituir, ele deverá seguir a ligação da janela Note para o documento, daí o bloco de texto ou gráfico no outro final da ligação será marcado.

O autor pode incorporar a mudança sugerida transferindo dados através da ligação entre a anotação e o draft. Se a janela ativa for um Note, o autor pode utilizar o comando Push. Por outro lado, se a janela ativa for o documento, o autor pode utilizar o comando Pull. Para facilitar essa atividade, evitando que o autor tenha que ficar lembrando qual comando (Push ou Pull) utilizar, existe um comando chamado "Incorporate Annotation" que faz a transferência do conteúdo da anotação através da ligação, dependendo se a janela ativa é um Note ou um documento. Mesmo incorporando a mudança sugerida por um anotador, o autor pode incorporar outra sugestão de outro anotador. O autor pode sempre refazer a incorporação e retornar ao documento original usando o comando "Undo" várias vezes.

\subsection{Considerações Finais}

Os sistemas hipermídia de segunda geração apresentados neste capítulo foram criados com objetivos diferentes, o que gerou mecanismos de anotações distintos e de várias complexidades. Por exemplo, o Guide possui um mecanismo de anotação bastante simples, pois o único tipo de anotação é feito pelo autor do documento para explicar melhor algum item de informação; ao leitor não é permitido fazer anotações. O mecanismo de anotações no NoteCards também é bastante simples, pois estruturalmente não há diferença entre um cartão que é utilizado para anotação e entre aquele utilizado para outros propósitos. Já o sistema KMS, por ser de uso geral, não possui um suporte específico de anotação, mas sugere que as anotações sejam feitas utilizando os ítens de anotação. O sistema Intermedia, por sua vez, possui um mecanismo de anotações mais complexo que os demais, pois trata a anotação como uma entidade de características próprias que possui atributos como título, criador e data de modificação. Além disso, possui mecanismos de incorporação da mudança sugerida ao documento anotado e uma estrutura que ordena e organiza as anotações de cada documento. 
Tanto o KMS quanto o Intermedia suportam acesso concorrente às suas estruturas, permitindo que múltiplos usuários criem anotações em um mesmo documento simultaneamente, desde que os usuários possuam as devidas permissões.

Do estudo realizado neste capítulo, alguns requisitos podem ser adotados na construção do serviço GroupNote, como:

- Anotações devem ser entidades com características próprias, não compartilhando da mesma definição dada à entidade documento. Assim, é possível distinguir anotações de documentos, e conseqüentemente será possível compartilhar as anotações e fazer buscas sobre atributos como autor, título e data de criação;

- Anotações podem anotar documentos ou existirem independentes deles;

- Anotações anotam o documento como um todo ou porções de tamanho variável do documento;

- Anotações podem ser armazenadas em repositórios (pastas) para melhor organização;

- Anotações devem ter permissões de acesso em um sistema multi-usuário; e

- Anotações podem formar uma estrutura hierárquica de anotações que respondem anotações, facilitando as discussões entre os usuários.

Em relação às interfaces de criação e de visualização de anotações, as características de tais sistemas hipermídia podem inspirar diversas aplicações dependendo da finalidade de cada uma. Trabalho recente [Wojahn et al., 1998] relata experiências dos efeitos de interfaces de anotação sobre a comunicação em uma tarefa colaborativa. 


\section{Capítulo 3}

\section{Anotações na Web}

\subsection{Considerações Iniciais}

A Web foi proposta como uma solução para a publicação de documentos científicos. Atualmente a Web tem sido utilizada nas mais diversas áreas, como: comércio eletrônico, ambientes educacionais, publicação de artigos científicos e repositórios de informação de modo geral.

O intuito deste capítulo é identificar anotações encontradas nesses diversos domínios de aplicação, compilando requisitos que podem ser incorporados à implementação do serviço GroupNote. Os requisitos levantados são apresentados na Seção 3.14 de considerações finais.

\subsection{Submarino - um Site de Comércio Eletrônico}

Submarino [Submarino, 2001] é uma empresa de comércio eletrônico do Brasil lançada em novembro de 1999 cujos produtos principais de venda são livros e CDs. Em 2001 o Submarino foi classificado entre os três melhores sites de venda ao consumidor.

No Submarino todo produto possui uma seção na qual os leitores podem opinar sobre o produto. Para inserir um comentário o leitor deve clicar sobre a âncora intitulada "O que Achei?", conforme apresentado na Figura 3.1, e uma janela é aberta com a descrição do produto e os seguintes campos: avaliação para o produto, título e conteúdo do comentário, 
nome, e-mail e cidade do leitor. A publicação do comentário na página do produto não é automática, uma avaliação preliminar é realizada para decidir se o comentário será publicado ou não.

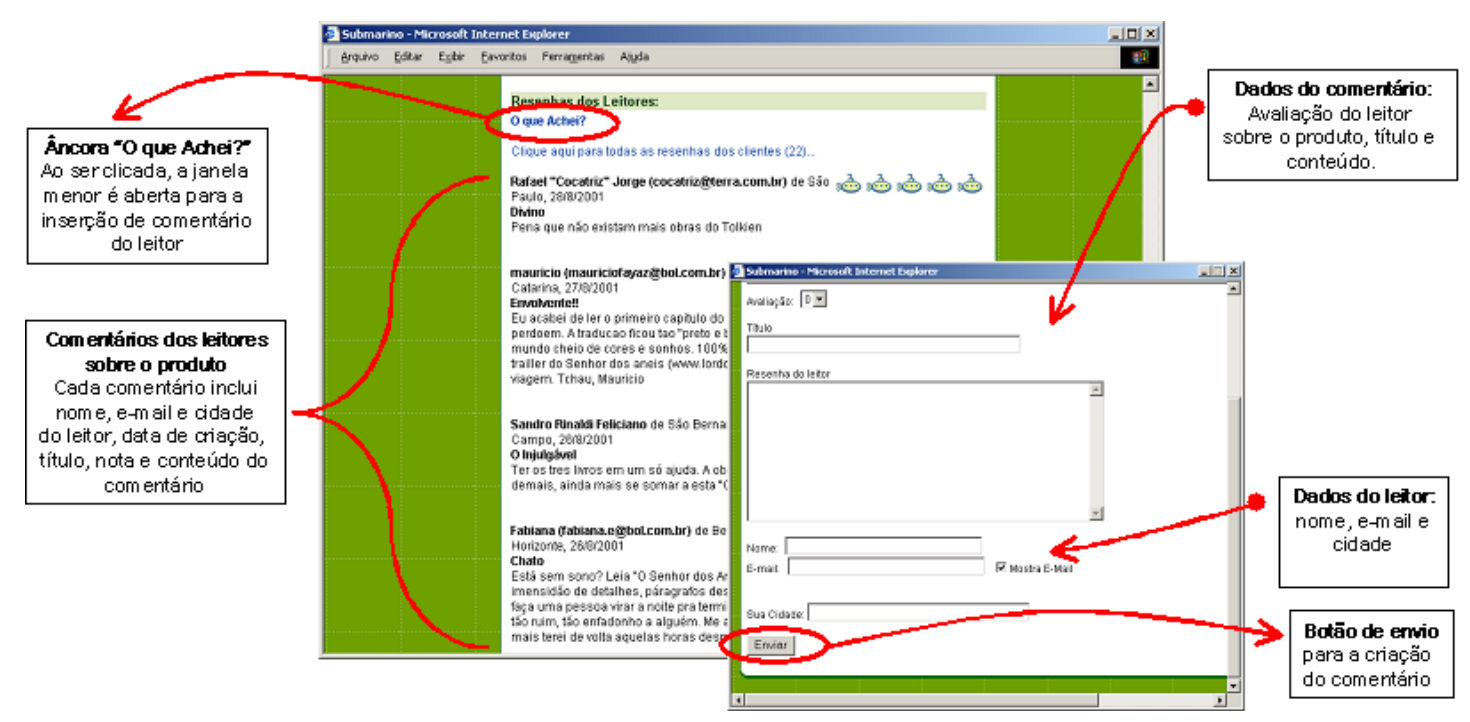

Figura 3.1: Anotação suportada pelo site de comércio eletrônico Submarino.

A Amazon [Amazon, 2001] e a livraria Cultura [Cultura, 2001] também são sites de comércio eletrônico que possuem um mecanismo de anotações semelhante ao do Submarino. Entretanto, na Amazon o usuário deve se registrar no sistema para fazer quaisquer comentários sobre os produtos.

\subsection{WebCT - uma Ferramenta para Criação de Cur- sos On-line}

WebCT [WebCT, 2001] é um conjunto de ferramentas criado em 1996 pelo grupo de Murraw W. Goldberg da University of British Columbia, Canadá, que possibilita a criação de ambientes educacionais na Internet. O WebCT pode ser utilizado para criar cursos on-line completos ou apenas como material de apoio a cursos.

No WebCT cada página de conteúdo didático possui um menu que suporta anotações individuais e fóruns de discussão ${ }^{1}$ dos alunos cadastrados no sistema. Para criar anotações individuais o aluno deve clicar o ícone "my notes" do menu. Com isso, uma janela é aberta com as seguintes características: (a) título do documento ao qual a anotação se refere e

\footnotetext{
${ }^{1}$ um fórum de discussão é um conjunto de anotações
} 
(b) as opções de (i) fechar janela, (ii) adicionar e apagar anotação, (iii) visualizar todas as anotações que o aluno realizou nos outros documentos do curso e (iv) listar todos os títulos dos documentos do curso para conseqüentemente visualizar as anotações do aluno no documento escolhido. Por outro lado, para fazer um comentário nos fóruns de discussão, o aluno deve clicar o ícone "bulletins" do menu e conseqüentemente a página atual é substituída pela página do fórum. O aluno deve escolher, então, a opção "Compose" do menu e uma janela é aberta referenciando a página sendo anotada. Essa janela possui características como "preview", anexação de um arquivo à anotação e configuração da fonte da escrita da anotação.

\subsection{AulaNet - um Ambiente para a Criação, Partici- pação e Administração de Cursos On-line}

AulaNet [Lucena and Fuks, 1998] é um ambiente para criação, participação e administração de cursos baseados na Web, cujo desenvolvimento vem se realizando desde 1997 no Laboratório de Engenharia de Software do Departamento de Informática da PUC-Rio. Pode ser utilizado tanto para ensino a distância como para complementação às atividades de educação presencial e treinamento de profissionais.

No AulaNet existem dois mecanismos de fóruns de discussão: Grupo de Discussão e Grupo de Interesse. No Grupo de Discussão, os participantes de um curso fazem discussões através do correio eletrônico do ambiente. Toda mensagem é enviada para a caixa de correio de todos os participantes do curso, além de ser armazenada no ambiente para futuras consultas. Essas mensagens são listadas seqüencialmente por ordem de data de criação. Já o Grupo de Interesse possibilita a criação de conferências assíncronas textuais na forma de discussão orientada para um tópico. As mensagens são apresentadas hierarquicamente, reforçando a idéia de relevância. Toda mensagem postada não é enviada para a caixa de correio dos participantes do curso, ficando somente armazenada no ambiente para futuras consultas. 


\subsection{IJHCS - um Site de Publicação de Artigos Cien- tíficos}

IJHCS (International Journal Human-Computer Studies) [IJHCS, 2001] é um site de publicação de artigos sobre a usabilidade na Web. Todo artigo pode ser comentado por quaisquer leitores, gerando um fórum de discussão. O IJHCS possui duas interfaces de visualização de comentários: o documento sendo comentado com os comentários na mesma janela (Figura 3.2a) e o documento sendo comentado com os comentários em janelas separadas (Figura 3.2b). A vantagem da primeira interface é que o leitor pode ver o documento e os comentários simultaneamente, mas apenas se a resolução for de 832x624 pixels ou mais.

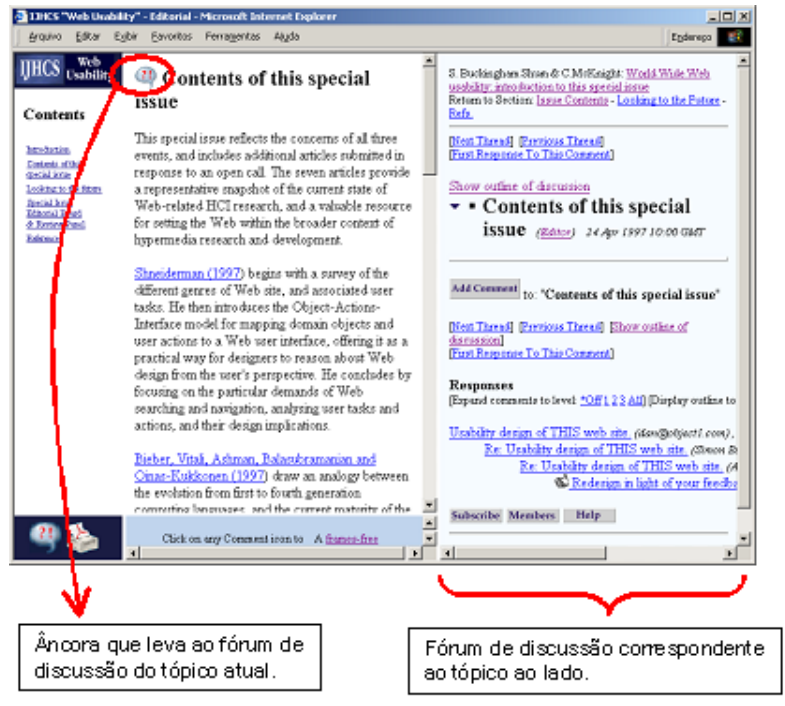

(a)

O documento sendo comentado e os comentários estão na mesma janela

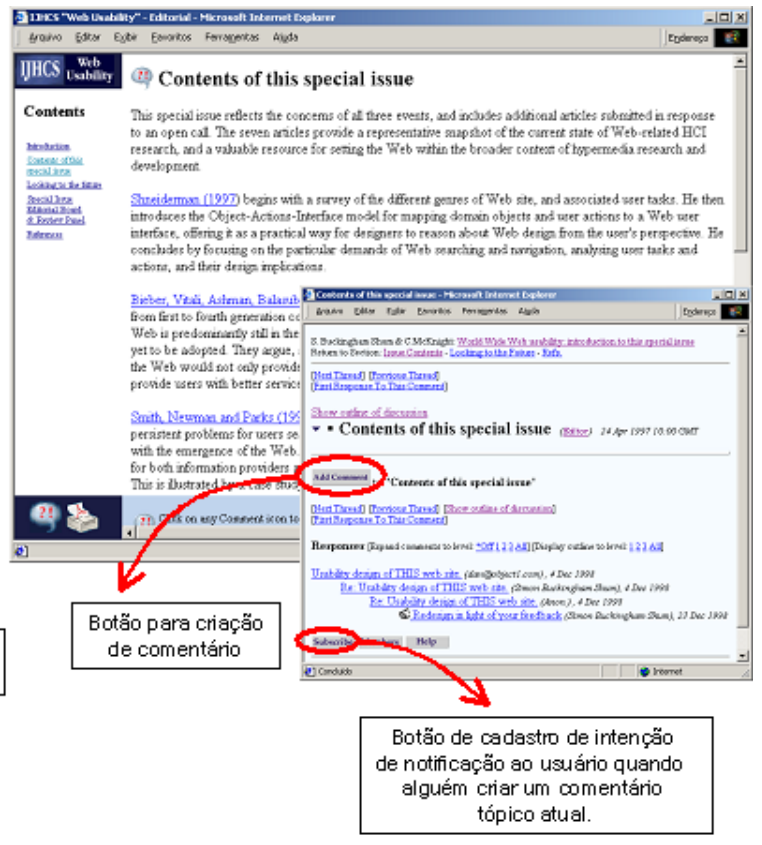

(b)

O documento sendo comentado e os comentários estão em janelas separadas

Figura 3.2: As duas interfaces de visualização de comentários do IJHCS.

A página de edição de comentário é muito bem comentada, explicando o que cada campo significa. O usuário pode optar por inserir uma anotação como anônimo e escolher a opção de "concorda" ou "discorda" do comentário anterior. Caso o usuário tenha se cadastrado no sistema, ele não precisa passar seus dados (nome e e-mail) toda a vez que fizer uma anotação. Esse cadastramento não possui segurança, é apenas uma maneira de identificar o usuário nas anotações; por isso, o usuário pode cadastrar um login e senha simples. O 
usuário também pode cadastrar sua intenção de ser notificado quando um comentário for adicionado àquele tópico.

\section{6 eClass - um Sistema de Captura e Acesso de Ex- periências "Ao vivo"}

O eClass [Abowd, 1999] é um projeto que vem sendo desenvolvido desde 1995 no Georgia Institute of Technology em Atlanta - EUA para a captura de aulas e reuniões utilizando a computação ubíqüa ${ }^{2}$. As aulas e reuniões capturadas são disponibilizadas em hiperdocumentos na Web para acesso após o evento. O conteúdo dos hiperdocumentos inclui: áudio, vídeo, slides apresentados e ligações para páginas Web visitadas.

O eClass possui dois tipos de anotações: (a) anotação do professor para explicar melhor o assunto relacionado ao slide atual. A inserção é realizada através de uma caixa de edição como mostrada na Figura 3.3. (b) Discussões entre alunos e professores sobre o slide atual como apresentado na Figura 3.4. Essa atividade é suportada por uma ferramenta colaborativa denominada CoWeb [Guzdial, 1998].

\subsection{CoWeb - uma Ferramenta para Autoria Colabo- rativa de Páginas Web}

CoWeb [Guzdial, 1998] é uma ferramenta assíncrona para autoria de páginas Web. Foi baseada no projeto colaborativo WikiWikiWeb de Ward Cunninghan e implementado pela equipe de Mark Guzdial no Laboratório de Software Colaborativo do Georgia Tech. No início de 1999 a CoWeb foi utilizada no Georgia Tech integrada aos hiperdocumentos do eClass, favorecendo a colaboração entre alunos e professores. Desde o início do ano 2000 vem sendo utilizada no ICMC em vários cursos.

O princípio básico da CoWeb é a autoria aberta, na qual qualquer pessoa pode editar e criar páginas CoWeb diretamente no browser. A CoWeb permite que usuários criem páginas com estrutura e conteúdo desejados. Entretanto, no projeto da CoWeb optou-se por não prover serviços específicos para anotações. Por exemplo, quando um indivíduo

\footnotetext{
${ }^{2}$ Segundo [Weiser, 1993], a computação ubíqüa objetiva aprimorar o uso de computação ao fazer com que muitos computadores estejam espalhados em um ambiente físico de modo transparente ao usuário.
} 


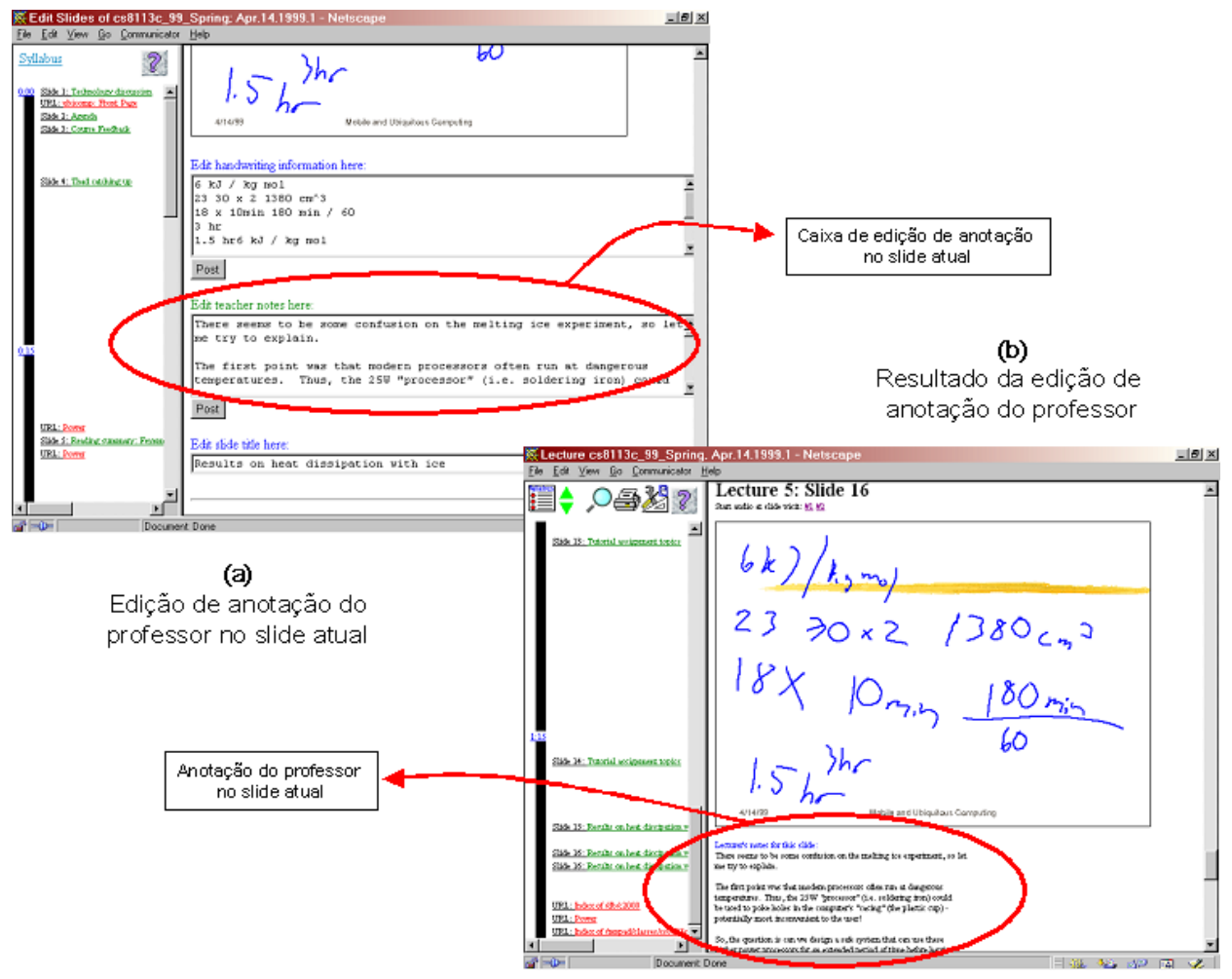

Figura 3.3: Anotação do professor no eClass.

deseja fazer comentários sobre textos em páginas CoWeb, ele deve indicar seus comentários de maneira que estes fiquem distinguíveis do texto primário, podendo ainda adicionar meta-informações como data de inserção e identificação do autor.

\subsection{NotePals - uma Aplicação que Executa sobre As- sistentes Digitais Pessoais}

NotePals [Davis et al., 1998] é uma aplicação para tomar notas de reuniões que executa sobre assistentes digitais pessoais (PDAs). Os participantes da reunião fazem anotações com suas próprias caligrafias sobre os PDAs através de canetas óticas. Após a reunião, as anotações são compartilhadas com outros participantes pela sincronização com um repositório de anotações compartilhadas. Essas anotações podem ser acessadas usando um browser Web e os participantes podem ordenar e filtrar as anotações por várias características, como projeto, autor, data, e tipo da anotação.

Um outro sistema de anotação utilizando caneta ótica, o StuPad [Truong and Abowd, 1999], também utiliza a Web para a publicação de anotações tomadas em salas de aulas. 


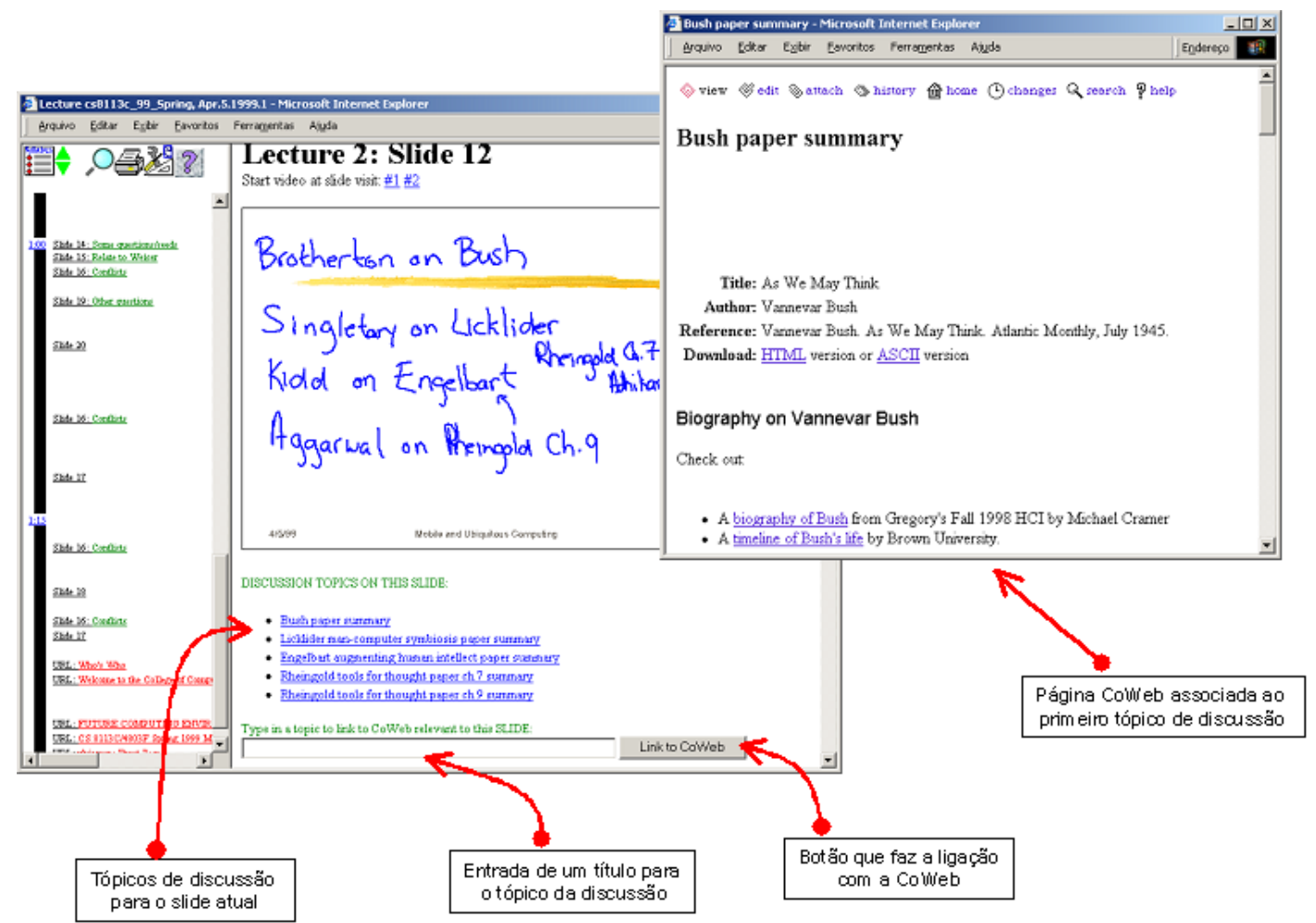

Figura 3.4: Anotações colaborativas entre alunos e professores no eClass através da ferramenta colaborativa CoWeb.

\subsection{Annotea - um Sistema de Anotação Aberto do W3C}

Annotea [Kahan et al., 2001] é um sistema de anotação aberto na Web criado pelo W3C que modela anotações como metadados. Esse sistema utiliza e contribui para o avanço dos padrões W3C: combinação de RDF com XPointer [W3C, 2001e], XLink [W3C, 2001d] e HTTP.

No Annotea, anotações são recursos Web de primeira classe e podem ser armazenadas em um ou mais servidores de anotação. O servidor de anotação armazena as anotações em uma base de dados RDF e toda a comunicação entre o cliente e o servidor utiliza métodos HTTP. RDF será explicado mais detalhadamente no Capítulo 4.

Uma anotação do Annotea é representada como um conjunto de metadados ${ }^{3}$ e um corpo de anotação. Os metadados são modelados através de um esquema RDF que fornece informações como data de criação da anotação, nome do autor, o documento anotado e

\footnotetext{
${ }^{3}$ Metadado é "dado sobre dado".
} 
um XPointer que especifica a porção do documento anotado.

Annotea implementa anotações privadas e compartilhadas. Anotações privadas são armazenadas localmente e restritas à máquina do usuário. Já as anotações compartilhadas são armazenadas na Web e podem ser lidas por todos os usuários registrados em um servidor remoto. O primeiro cliente do Annotea foi o editor e browser Amaya [W3C, 2001a]. Na Figura 3.5 é mostrado como é feita uma anotação em um documento Web utilizando o browser Amaya com o Annotea. Para identificar as anotações em um documento Web é utilizado um ícone em forma de lápis em frente à porção anotada. Recentemente o Annotea está sendo implementado no browser Mozzila [mozdev.org, 2001].

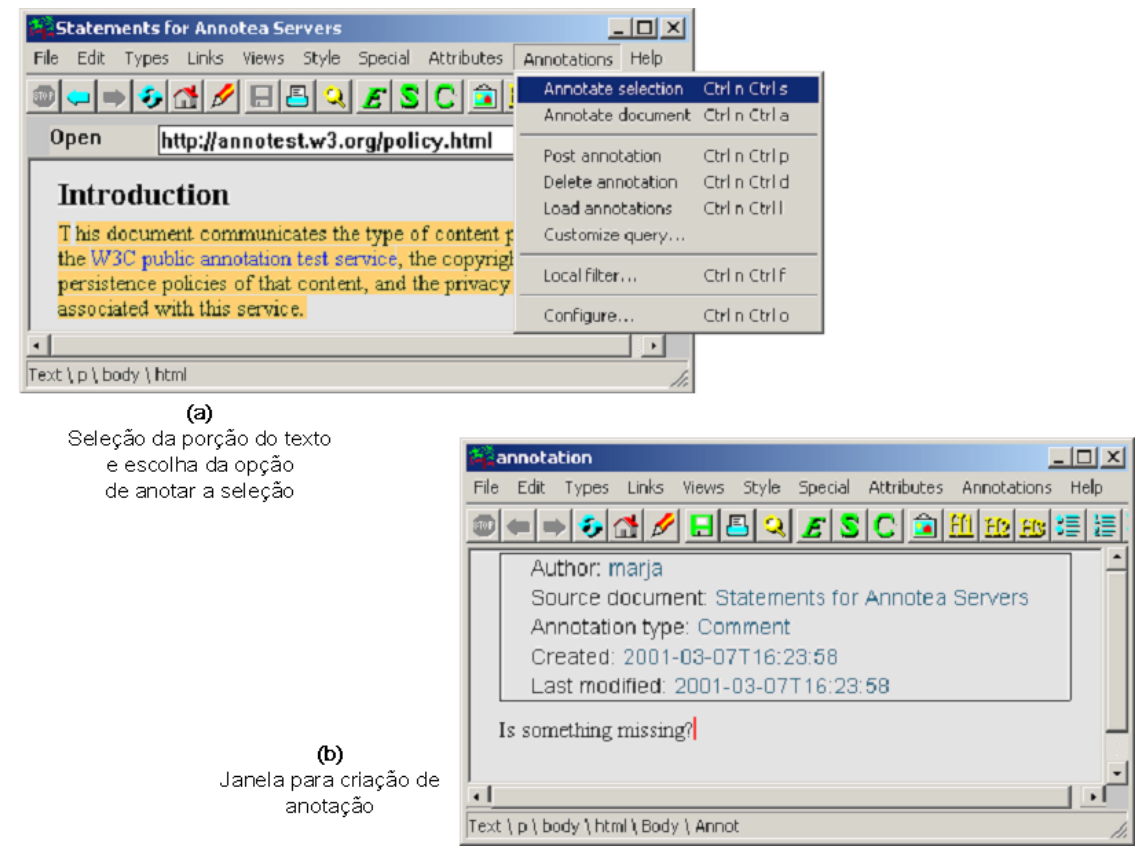

Figura 3.5: Anotações em documentos Web utilizando o browser e editor Amaya com o serviço de anotações Annotea.

\section{Protocolos Annotea}

Um cliente interage com servidores de anotação Annotea usando HTTP. Existem cinco tipos de interações cliente-servidor:

- Criar uma anotação: o cliente publica uma nova anotação;

- Consultar o servidor de anotação: o cliente envia uma consulta ao servidor e obtém a anotação; 
- Obter o corpo de uma anotação;

- Atualizar uma anotação: o cliente modifica uma anotação e publica essas modificações; e

- Apagar uma anotação: o cliente apaga uma anotação do servidor.

O método POST do HTTP é usado para armazenar uma nova anotação no servidor, e o método GET é usado para buscar anotações e retornar o resultado ao cliente. O método POST fornece a interface necessária para o servidor construir um URI para a nova anotação e retorná-lo ao cliente. Quando o cliente possui um URI para a anotação criada, ele pode (com as devidas permissões) (a) usar o método PUT para modificar a anotação, e (b) usar o método DELETE para apagar uma anotação. O código-fonte do Annotea encontra-se disponível na Web.

\subsection{CoNote - um Sistema Colaborativo de Anotações}

CoNote [Davis and Huttenlocher, 1995] é um sistema de anotação na Web desenvolvido na Cornell University para fornecer um mecanismo mais adequado para a colaboração entre estudantes e professores. A idéia central desse sistema é que os documentos sendo anotados fornecem um contexto para discussões em grupo, permitindo que as pessoas encontrem discussões sobre tópicos particulares mais rapidamente.

No CoNote as anotações são limitadas a locais (pontos de anotação) determinados pelo autor do documento. Em um ponto de anotação existem ligações para todas as anotações existentes naquele ponto. Essas anotações são arranjadas em uma árvore com os seguintes atributos: título e data de criação da anotação e o nome do criador.

O processo de colaboração do CoNote é baseado no conceito de grupos de pessoas que compartilham uma coleção de documentos. Cada pessoa do grupo possui um papel em relação aos documentos naquele grupo. Os papéis são: viewer, reader, user e author. Um viewer pode ver os documentos anotados mas não pode ver as anotações sobre ele. Um reader pode ver as anotações, mas não pode adicionar qualquer anotação. Um user pode ler e adicionar, e um author pode ler, adicionar e apagar anotações. Uma pessoa pode fazer parte de vários grupos e ter diferentes papéis em cada um deles. Os grupos podem definir um papel padrão para usuários não registrados. 
O CoNote é implementado em Perl e as anotações são armazenadas no sistema de arquivo no servidor e separadas em grupos. O código-fonte está disponível na Web.

\subsection{ComMentor - um Sistema de Anotação Imple- mentado como um Browser Web}

ComMentor [Röscheisen et al., 1995] é um sistema de anotação desenvolvido pelo Stanford Integrated Digital Library Project e implementado como um browser Web (baseado no NCSA xMosaic 2.4) com extensões para dar suporte a anotações. Uma implementação do protótipo foi finalizada em 1994 e testada localmente.

No ComMentor as anotações podem ser públicas, privadas ou designadas a um grupo, permitindo aos usuários anotarem páginas arbitrárias em qualquer ponto do documento. As informações sobre anotações, grupos e usuários são armazenadas em servidores de meta-informação. Essas meta-informações são descritas em PRDM (Partial Redundant Descriptive Meta-language).

O ComMentor foi implementado através de scripts CGI escritos em Perl e não encontra-se mais em uso. O código-fonte não está mais disponibilizado na Web.

\subsection{CritLink - um Sistema de Anotação Implemen- tado como um Mediador}

CritLink [Yee, 1999] é um sistema de anotação desenvolvido por Ka-Ping Yee na Universidade de Waterloo para permitir que quaisquer leitores anotem quaisquer páginas Web. O CritLink utiliza o HyperWave, apresentado na próxima seção, para implementar as suas funcionalidades. O CritLink está disponível para uso livre na Web em http: //www.crit.org.

CritLink funciona basicamente como um programa mediador que recebe o pedido do cliente, através da entrada do endereço da página desejada em uma caixa de edição (Figura 3.6), e contata o servidor Web que busca o documento; o mediador então processa o documento e o apresenta ao usuário. Nesse processamento são inseridas (a) ligações para anotações armazenadas no servidor de anotações, (b) ligações para docu- 
mentos que apontam para o documento atual, (c) uma âncora para adicionar anotações, e (d) uma caixa de edição no topo da página para o leitor entrar com outros endereços de documentos Web.

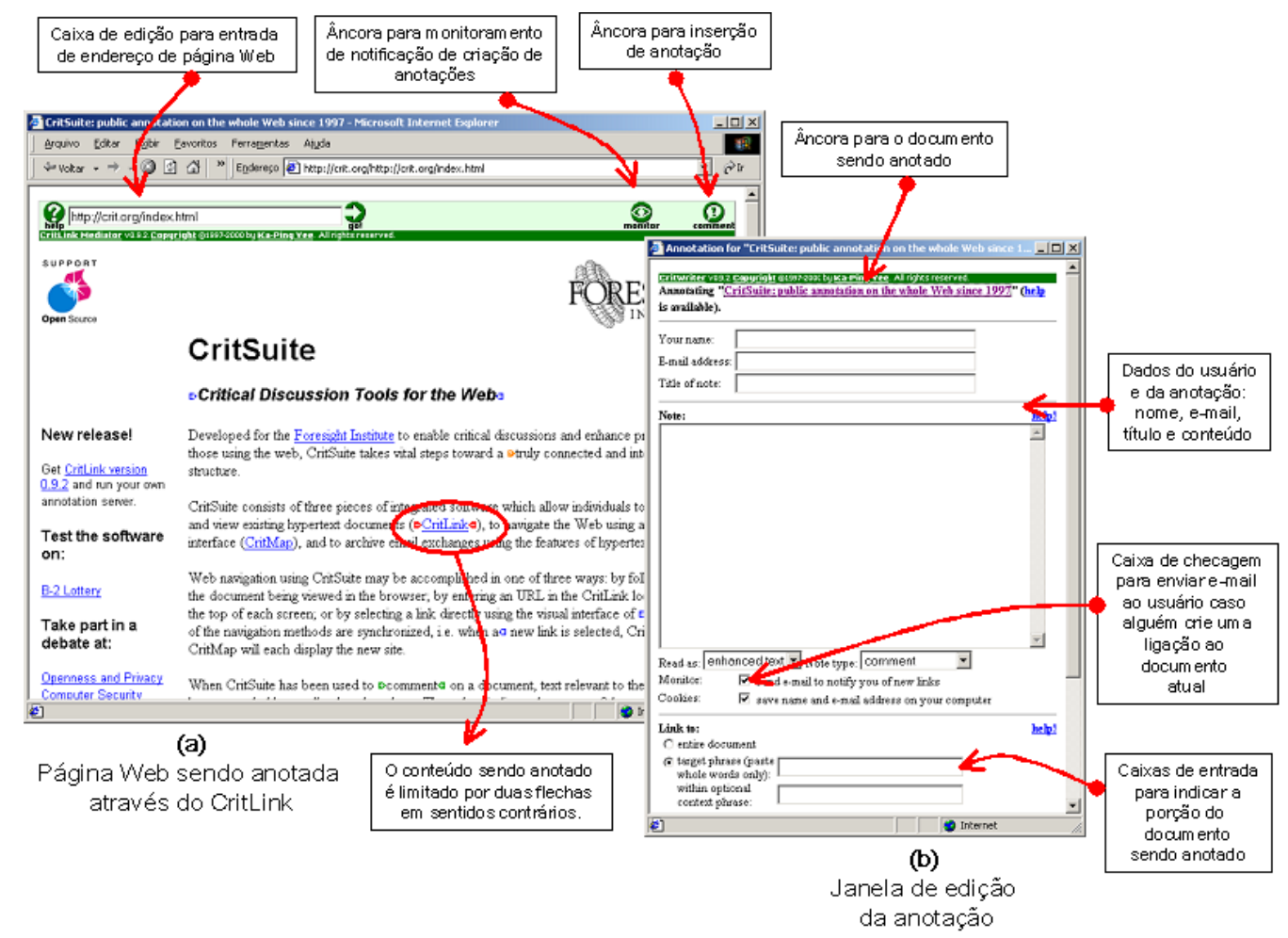

Figura 3.6: Interface de anotações no CritLink.

As anotações podem ser públicas ou privadas, podendo ser feitas em qualquer ponto do documento. Entretanto, o processo de adicionar uma anotação é um tanto trabalhosa, pois o trecho anotado deve ser digitado duas vezes no formulário de edição.

A presença de anotações no documento é indicada por duas flechas em sentidos contrários como mostrada na Figura 3.6. O leitor pode ver o título da anotação passando o mouse sobre uma das flechas e, ao clicá-la, o documento atual é substituído pelo conteúdo da anotação. Após criar a anotação o usuário recebe um e-mail contendo uma senha para ser utilizado na alteração ou deleção da anotação. O CritLink não possui um mecanismo de busca de anotações. 


\subsection{HyperWave - um Ambiente de Gerenciamento Avançado de Documentos}

HyperWave [Maurer, 1996] é um ambiente de gerenciamento avançado de documentos que permite que usuários remotos naveguem, anotem e façam manutenção de documentos distribuídos sobre a Web. HyperWave é a versão comercial do Hyper-G [Andrews et al., 1995], um sistema hipermídia de segunda geração.

O HyperWave é utilizado pelo CritLink, apresentado na seção anterior, e possui as seguintes características:

- Pode ser acessado por browsers Web como Microsoft Internet Explorer e Netscape;

- Implementa uma base de dados hipermídia totalmente orientada a objetos que permite integrar todas as mídias digitais tais como hipertexto, áudio, vídeo e animações;

- Protege documentos com direitos de acesso para usuário e grupo como no UNIX;

- Possui ligações bidirecionais;

- Possui ligações extrínsicas, ou seja, ligações que podem ser vistas sem a permissão do autor do documento;

- As ligações possuem rótulos, ou seja, a habilidade de rotular uma ligação com uma palavra-chave descrevendo seu tipo (por exemplo, "crítica", "exemplo"). Anotações são um tipo de ligação explícita;

- As ligações podem ligar qualquer porção de um documento, seja uma palavra ou uma letra; e

- Possui buscas sofisticadas como buscas sobre documentos PostScript.

\subsection{Considerações Finais}

Do estudo de anotações na Web, verificou-se que, além dos requisitos apontados no capítulo anterior, outros requisitos surgem para o serviço de anotações:

- O serviço de anotações deve estar disponível na Web devido a sua grande disseminação; 
- O serviço de anotações deve servir a várias aplicações;

- Anotações devem ser definidas através da XML para intercâmbio de dados, pois é uma linguagem de marcação apropriada à representação de dados, cuja essência fundamenta-se na capacidade de agregar informações. Isso favorece a interoperabilidade entre aplicações;

- Anotações devem estar associadas a metadados, atribuindo-lhes um significado bem definido, permitindo seu uso por humanos e computadores;

- Dar suporte à notificação de eventos, um recurso importante quando há interações de vários usuários sobre objetos compartilhados, conforme apresentado na Seção 3.5 sobre o site IJHCS; e

- Deve-se adotar tecnologias abertas para facilitar a extensão do serviço de anotações e suportar interoperabilidade entre aplicações. 


\section{Capítulo 4}

\section{Resource Description Framework (RDF)}

\subsection{Considerações Iniciais}

Devido ao fato de grande parte da Web ter sido construída principalmente para ser compreensível aos humanos e não aos computadores, é difícil automatizar quaisquer tarefas que tenham que ser executadas sobre a Web. Assim, quando se utiliza um serviço de busca como AltaVista ou Yahoo, por exemplo, sabe-se que muitos resultados não estarão relacionados ao tópico pedido.

A solução proposta pelo W3C para tornar a informação Web compreensível por computadores, e conseqüentemente facilitar a automatização de tarefas na Web, é o fornecimento de um mecanismo que permite a descrição de metadados relacionados a qualquer recurso Web: o RDF (Resource Description Framework) [W3C, 1999b].

O Grupo de Trabalho RDF do W3C é composto por integrantes de grandes organizações como Netscape, Microsoft, IBM e Nokia. O interesse de grandes vendedores de browsers Web no desenvolvimento do RDF promete um desenvolvimento em larga escala de ferramentas que processem RDF, levando à adoção em larga escala do RDF na Web.

São três os componentes de RDF: o modelo de dados, a sintaxe para intercâmbio de metadados, e o esquema. Esses componentes são apresentados, respectivamente, nas Seções 4.2, 4.3 e 4.4. O intuito deste capítulo é apresentar os principais aspectos de cada componente, uma vez que foram utilizados no serviço GroupNote. O modelo e sintaxe 
RDF são recomendações W3C desde fevereiro de 1999. As considerações finais deste capítulo são apresentadas na Seção 4.5.

\subsection{Modelo de Dados RDF}

O modelo de dados RDF fornece uma estrutura conceitual e abstrata para definir metadados. O modelo de dados consiste em três tipos de objetos:

- Recursos: são sempre denominados por URIs mais identificadores opcionais de âncora. Geralmente os recursos são páginas Web, mas podem ser uma parte de uma página Web (por exemplo, elemento HTML ou XML), uma coleção inteira de páginas (por exemplo, um Web site), ou até mesmo objetos que não são diretamente acessíveis via Web (por exemplo, livro impresso).

- Propriedades: são aspectos, características, atributos, ou relações específicas usadas para descrever um recurso (por exemplo, uma propriedade do recurso http://www . w3. org/Schema\#dev é a data de revisão). Cada propriedade possui um significado específico, define seus valores permitidos, os tipos de recursos que descreve e seus relacionamentos com outras propriedades.

- Statements: são triplas formadas por recursos, propriedades e valores das propriedades. O valor de uma propriedade pode ser um outro recurso ou um literal. Um literal geralmente é uma cadeia de caracteres (string). Um exemplo de um statement é mostrado a seguir:

"A data de revisão de http://www.w3.org/XML/Schema\#dev possui valor 2001/06/14"

Essa sentença é composta das partes Recurso, Propriedade e Valor, detalhadas na Tabela 4.1 .

Tabela 4.1: As partes de um statement RDF: recurso, propriedade e valor.

\begin{tabular}{|l||l|}
\hline Recurso & http://www.w3.org/XML/Schema\#dev \\
\hline Propriedade & data de revisão \\
\hline Valor & "2001/06/14" \\
\hline
\end{tabular}

Um statement também pode ser representado por um grafo dirigido rotulado, também chamado de "diagrama de nós e arcos", como apresentado na Figura 4.1. O recurso é representado por um nó oval, o valor da propriedade é representado por um nó retangular, 
e a propriedade é representada por um arco que conecta o recurso ao valor da propriedade. Essa notação é sugerida por [W3C, 1999a].

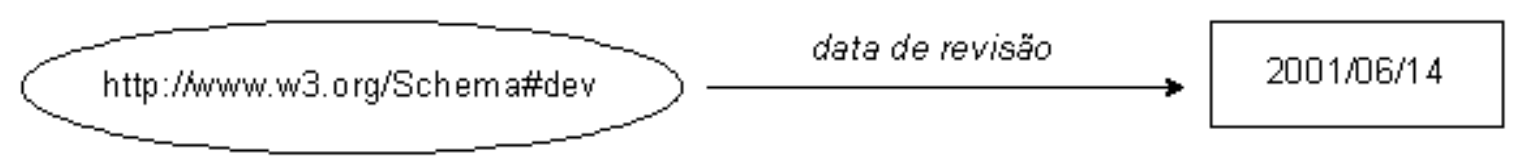

Figura 4.1: Exemplo de um statement RDF representado por um diagrama de nós e arcos.

\subsection{Sintaxe RDF}

Como dito anteriormente, o modelo de dados RDF fornece uma estrutura conceitual e abstrata para definir metadados. Entretanto, uma sintaxe concreta é necessária para a criação e intercâmbio de metadados. Namespaces XML também são utilizados para associar cada propriedade ao esquema que a define. Esquemas RDF são apresentados na próxima seção.

Existem duas sintaxes XML para codificar uma instância do modelo de dados: a sintaxe de serialização e a sintaxe abreviada. A sintaxe de serialização mostra claramente a estrutura de um modelo RDF e a sintaxe abreviada fornece uma forma mais compacta de representar o modelo de dados. Espera-se que os interpretadores RDF implementem ambas as sintaxes e os autores de metadados estejam livres para utilizá-las e combiná-las.

\section{Sintaxe de serialização RDF}

A sintaxe de serialização possui a forma apresentada na notação EBNF (Extended BackusNaur Form) [W3C, 1999a] como descrita abaixo.

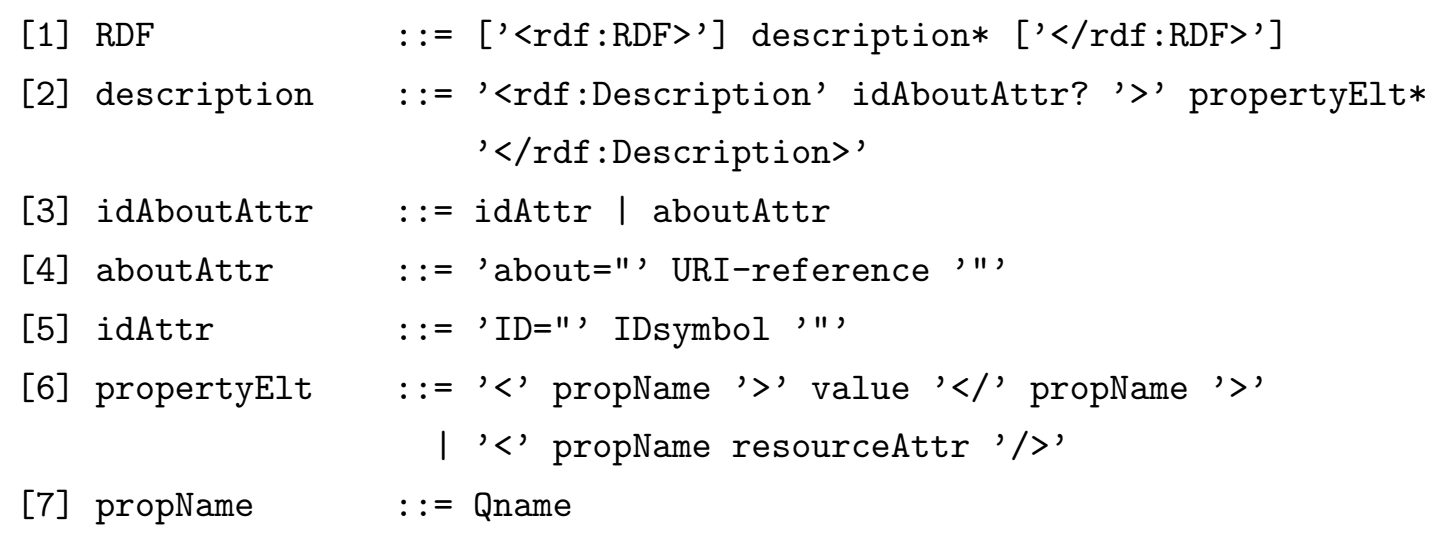




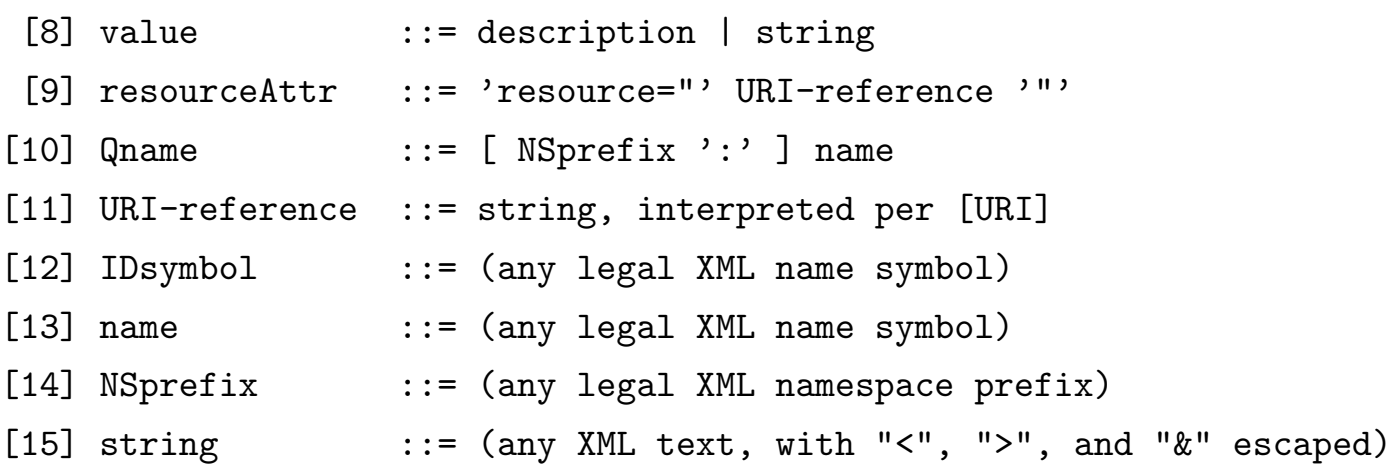

O conteúdo entre os elementos $\langle r d f: R D F\rangle$ e $\langle/ r d f: R D F\rangle$ em um documento XML representa uma instância do modelo de dados RDF. O elemento Description é utilizado para agrupar múltiplos statements em um mesmo recurso, ou seja, fornece uma maneira de atribuir um nome ao recurso apenas uma vez para vários statements. O nome utilizado para representar o recurso é inserido no atributo about caso o recurso exista, ou inserido no atributo ID caso contrário. Um único Description pode conter mais de um elemento propertyEl com o mesmo nome de propriedade.

O exemplo da sentença da Seção 4.2:

"A data de revisão de http://www.w3.org/XML/Schema\#dev possui valor 2001/06/14"

é representado em RDF/XML como apresentado abaixo:

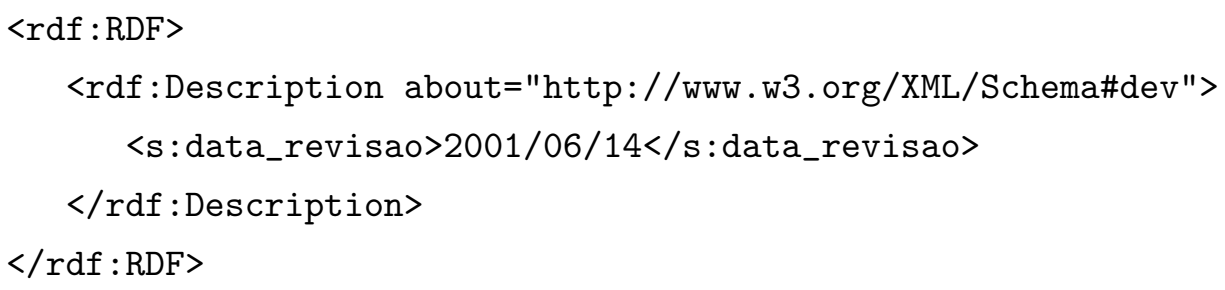

O prefixo 's' refere-se a um namespace específico escolhido pelo autor dessa expressão e definido em uma declaração de namespace XML como: xmlns:s="http://description. org/schema/".

O documento XML completo contendo a instância do modelo de dados RDF é apresentado a seguir.

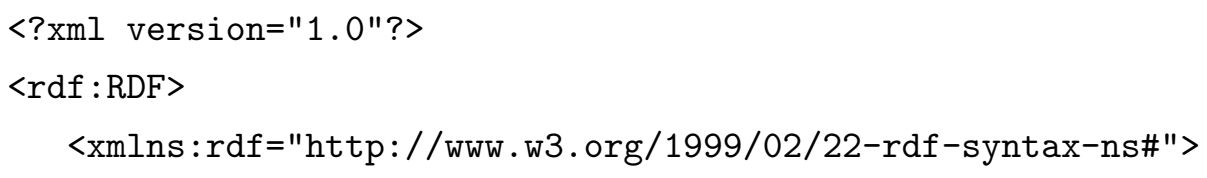




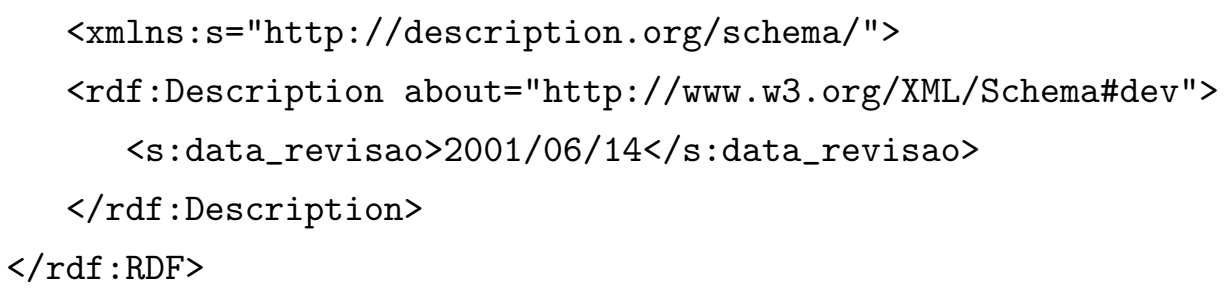

Verificando o exemplo acima, percebe-se que, quando expressões são altamente condensadas e escritas à mão, a utilização da sintaxe de serialização é desencorajadora e aumenta a possibilidade da sintaxe estar errada.

\section{Sintaxe abreviada RDF}

Existem três formas de sintaxe abreviada:

1. A primeira é usada quando as propriedades não são repetidas dentro de um Description e cujos valores são literais.

2. A segunda é empregada quando o valor de um statement é um outro recurso, e os valores das propriedades desse recurso são strings.

3. A terceira se aplica quando um elemento Description contém a propriedade type ${ }^{1}$. Nesse caso, o recurso type definido no esquema correspondente ao valor da propriedade type pode ser diretamente usado como um nome de elemento.

Exemplo da primeira forma de sintaxe abreviada: Suponha que o recurso http://www . w3. org possua as seguintes propriedades que não se repetem: editor, título e data. A sintaxe de serialização é a seguinte:

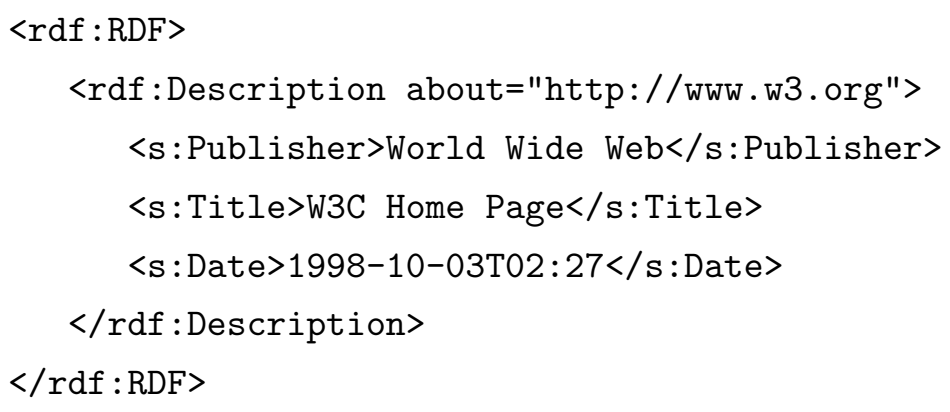

\footnotetext{
${ }^{1} \mathrm{O}$ valor da propriedade type descreve o tipo do novo recurso
} 
A sintaxe abreviada correspondente é obtida tornando as propriedades como atributos XML do elemento Description e utilizando a sintaxe de elemento XML vazio para representar o fechamento do elemento Description, como apresentada a seguir:

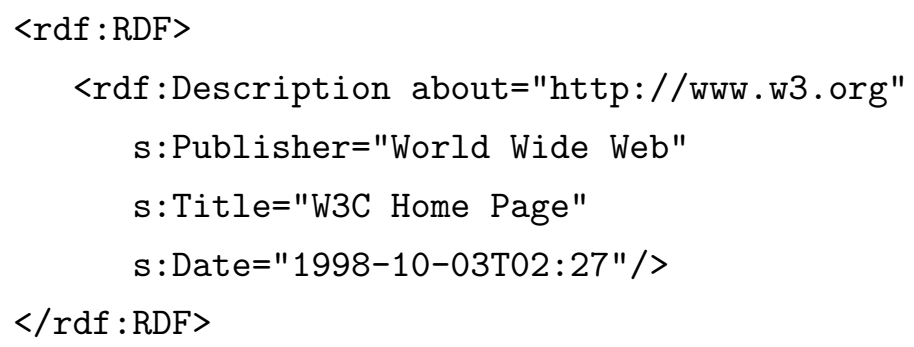

Embora essas duas expressões RDF sejam equivalentes, elas podem ser tratadas diferentemente por programas de busca e indexação na Web. Por exemplo, se essas expressões estivessem embutidas em um documento HTML, o comportamento padrão de um browser que não reconheça RDF é mostrar os valores das propriedades no primeiro caso, enquanto que no segundo caso nenhum texto é mostrado.

Exemplo da segunda forma de sintaxe abreviada: Suponha que um indivíduo referenciado pelo identificador de empregado 85740 é chamado de Ora Lassila e possui endereço eletrônico lassila@w3.org. O recurso http://www.w3.org/Home/Lassila foi criado por esse indivíduo. A sintaxe de serialização é a seguinte:

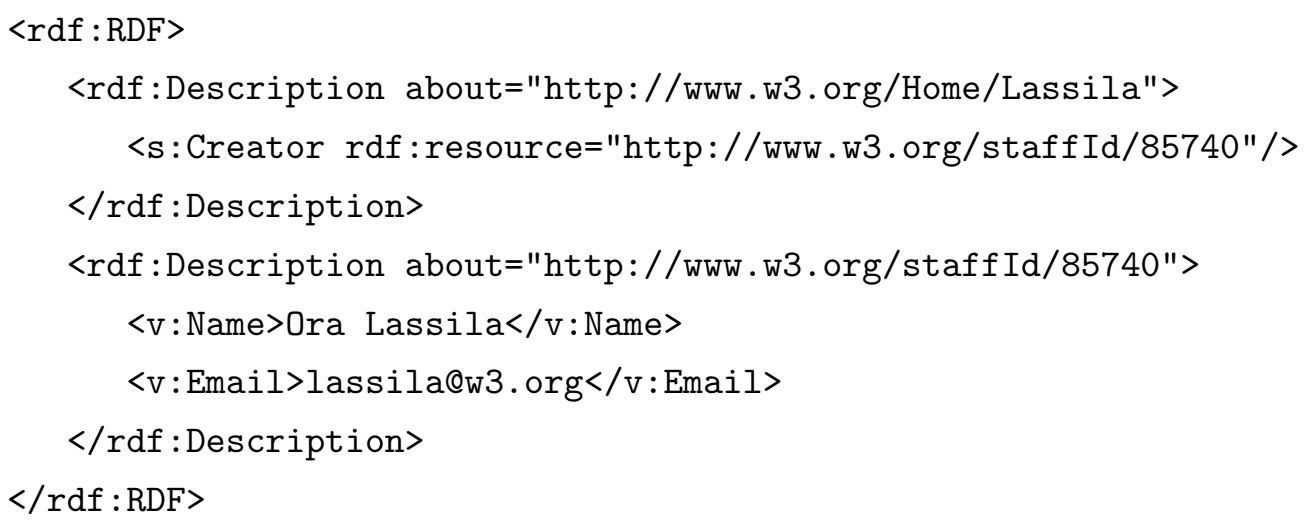

A sintaxe abreviada correspondente é obtida tornando as propriedades do recurso http://www.w3.org/staff Id/85740 e o próprio recurso como atributos de Creator, conforme apresentado a seguir. 


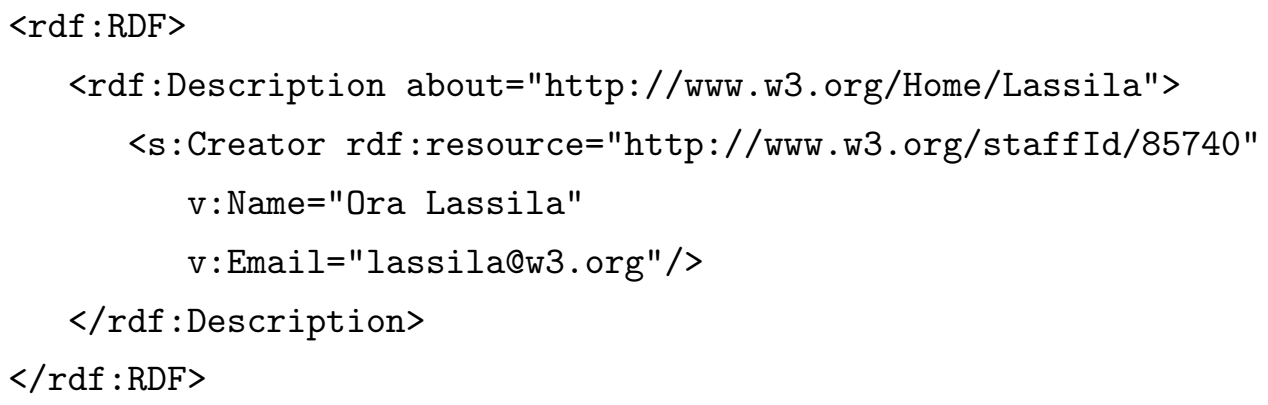

Exemplo da terceira forma de sintaxe abreviada: Suponha o exemplo anterior com o fato que o recurso http://www.w3.org/staff Id/85740 representa uma instância de uma pessoa, ou seja, pessoa é o tipo do recurso http://www.w3.org/staffId/85740. A sintaxe de serialização é apresentada a seguir.

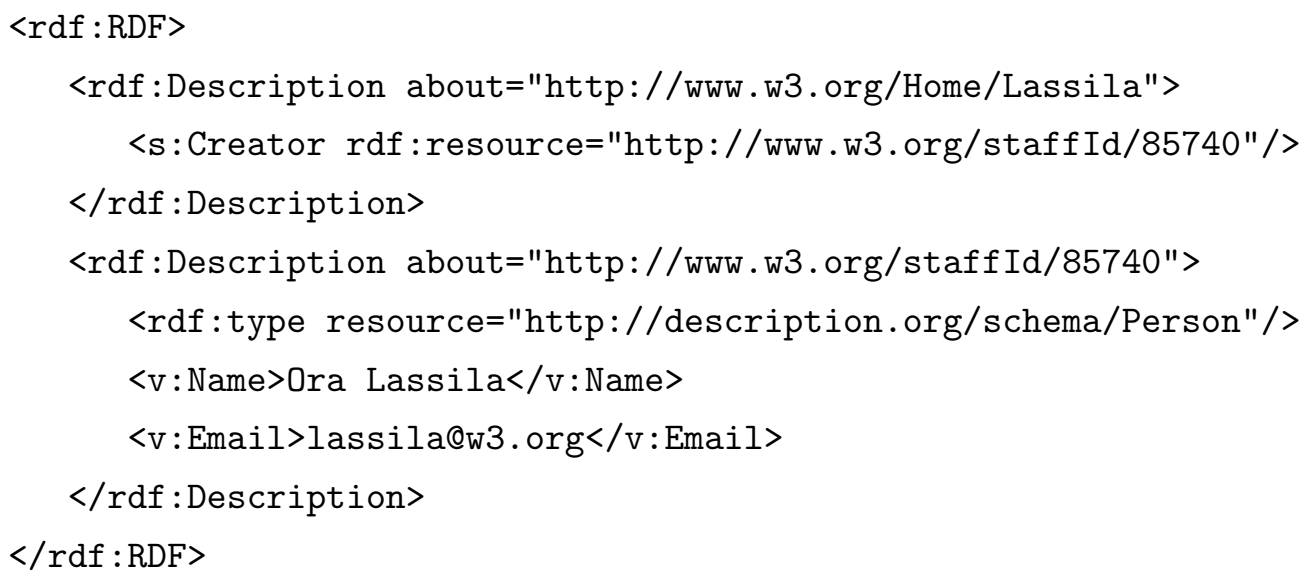

A sintaxe abreviada correspondente é obtida com a utilização do valor da propriedade type, no caso Person, usado diretamente como um nome de elemento, conforme apresentado a seguir:

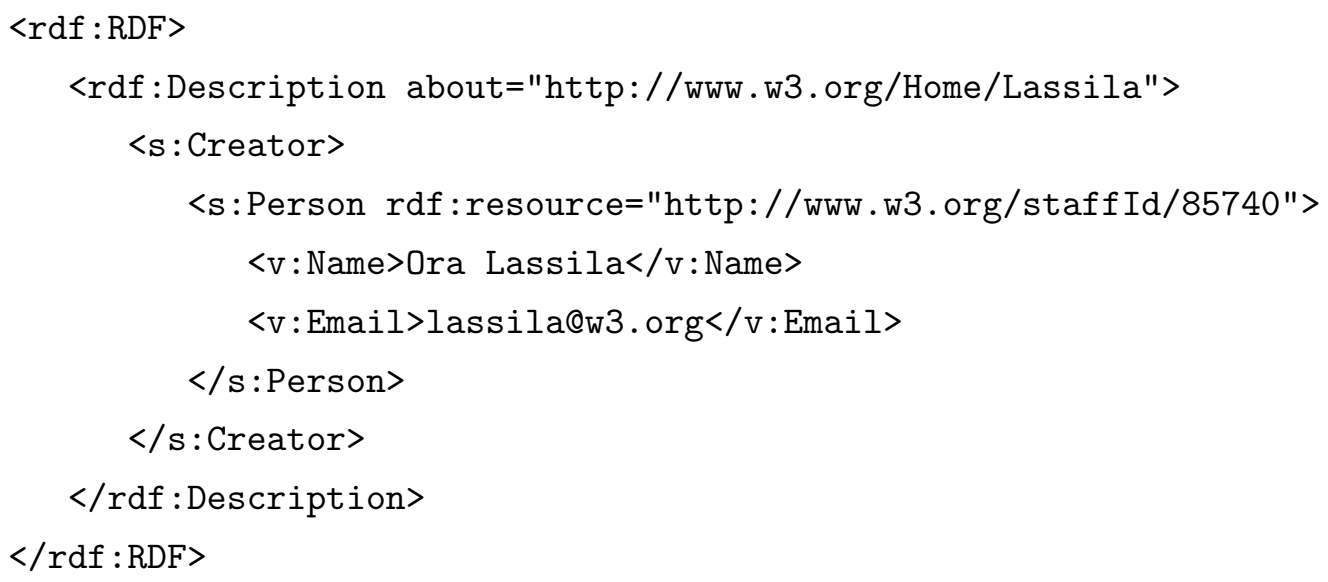




\subsection{Esquema RDF}

O modelo de dados define um modelo simples para descrever inter-relacionamentos entre recursos em termos de propriedades e valores. Entretanto, não fornece mecanismos para definir as propriedades (por exemplo, título, autor, tamanho, cor, tec ), para definir os relacionamentos entre as propriedades e recursos, e nem para definir os tipos de recursos sendo descritos (por exemplo, livros, páginas Web, pessoas, etc.). Esse é o papel do Esquema RDF [W3C, 2000], Recomendação Candidata do W3C desde março de 2000.

Esquemas RDF podem ser comparados a Definições de Tipo de Documento XML (DTDs) e Esquemas XML. Diferente de um DTD ou Esquema XML, que fornecem restrições sobre a estrutura de um documento XML, um Esquema RDF fornece informação sobre a interpretação dos statements em um modelo de dados RDF.

Para melhor entendimento das funcionalidades oferecidas pelo Esquema RDF, bem como de sua respectiva sintaxe em XML, um exemplo é apresentado a seguir.

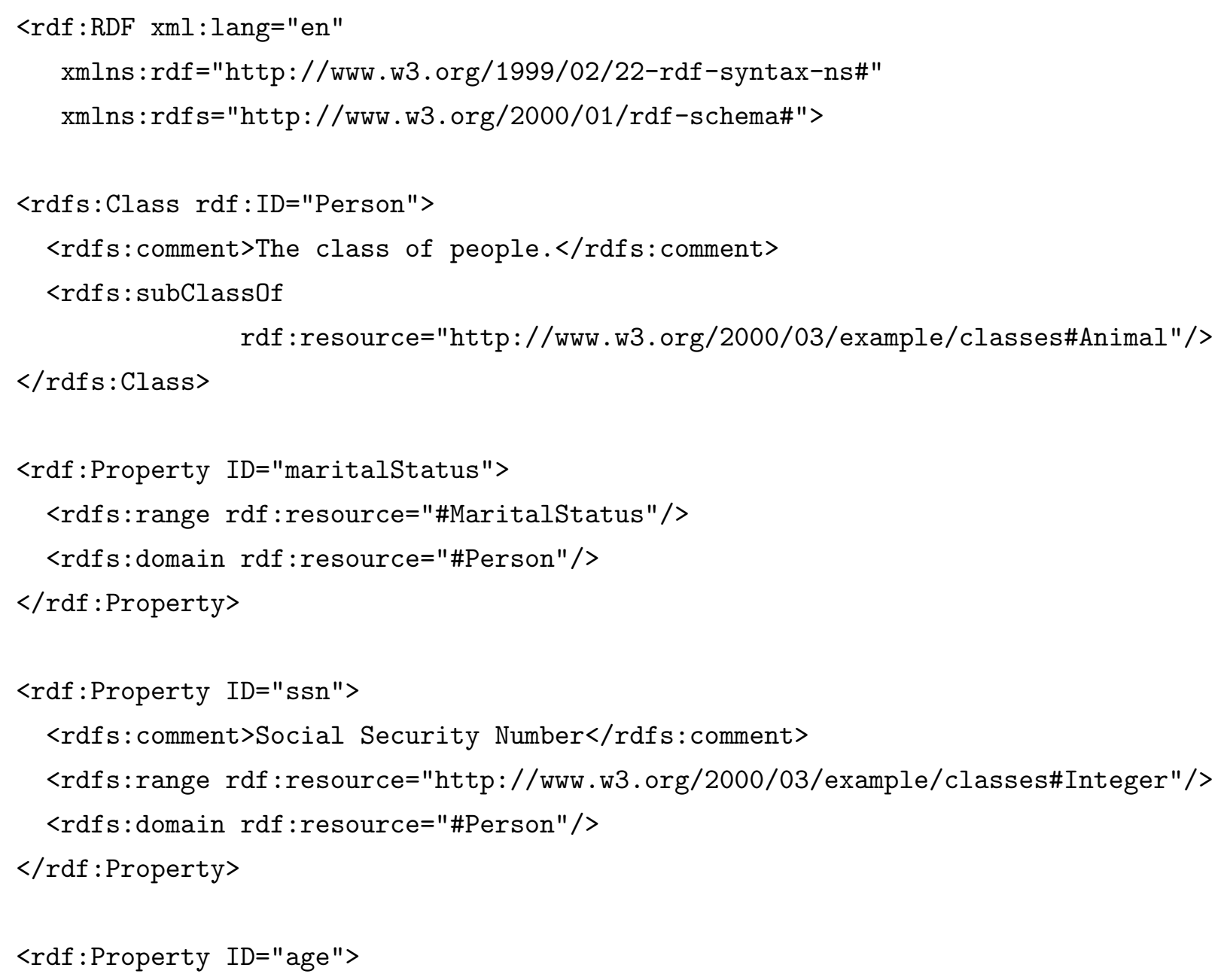




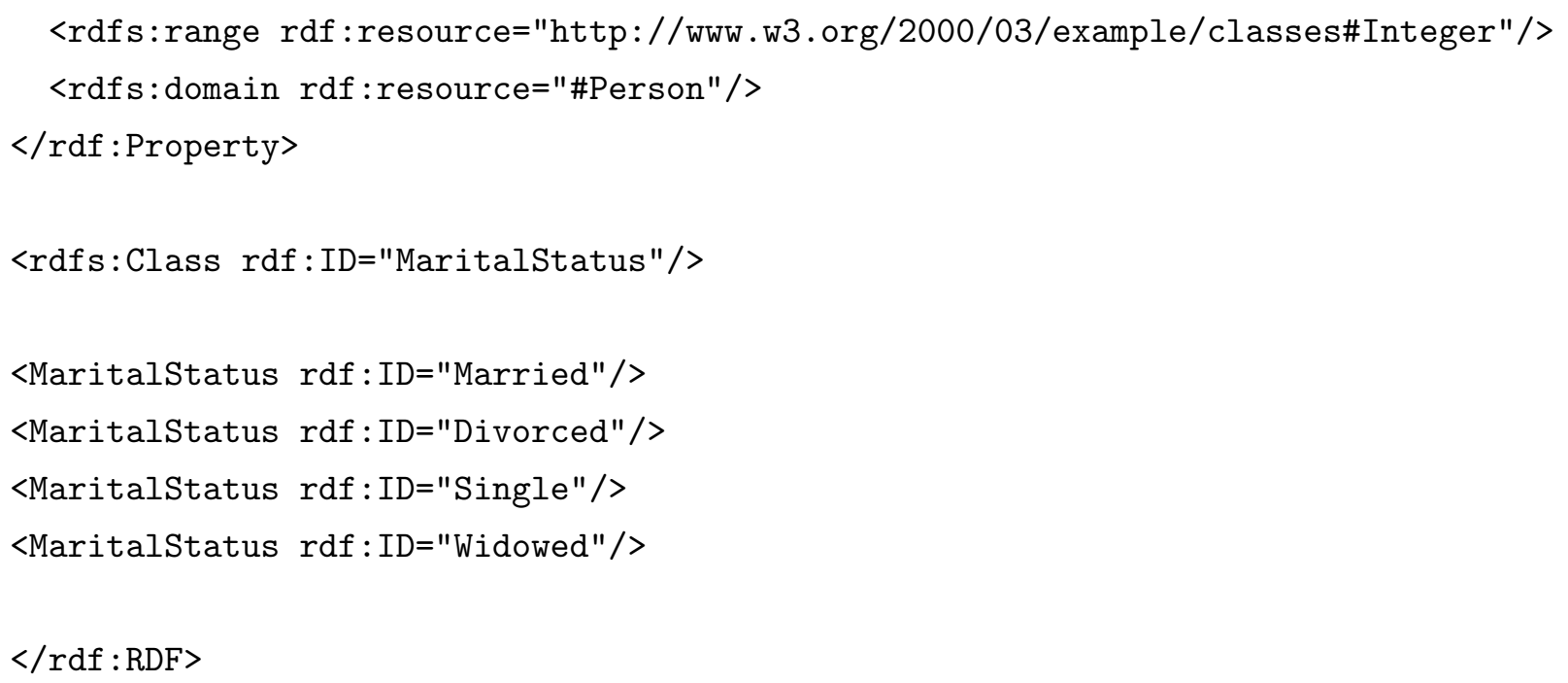

O núcleo dos vocabulários do RDF e do Esquema RDF são definidos, respectivamente, nos namespaces XML rdf e rdfs. O idioma da documentação é suportada pela utilização do elemento xml: lang. No exemplo, os recursos definidos no Esquema RDF estão no idioma inglês, segundo a notação xml : lang='en'.

Person é uma classe, denotada através de rdfs:Class, com a seguinte descrição compreensível por humanos: "The class of people". Essa descrição é denotada através de comment, que é uma propriedade utilizada para documentação.

Todas as pessoas são animais. Assim, Person é subclasse de Animal. Essa relação é denotada por rdfs:subClass0f. A classe Animal é definida em um outro esquema. A propriedade rdfs:domain é utilizada para indicar as classes que as propriedades podem ser usadas. Por exemplo, as propriedades MaritalStatus, ssn e age só podem ser usadas na classe Person.

Uma pessoa pode possuir as propriedades age e ssn, cujos valores são inteiros. Essa relação é denotada pela restrição rdfs:range. A classe Integer é definida em um outro esquema. O estado civil de uma pessoa pode ser: Single, Married, Divorced e Widowed. Essa relação também é obtida através do uso da restrição rdfs:range.

\subsection{Considerações Finais}

RDF é a base para o processamento de metadados; ele provê mecanismos para que informações sejam compreensíveis por computadores. Uma vez que a Web tenha sido sufici- 
entemente popularizada com metadados, espera-se que a busca sobre a Web se torne mais fácil porque os programas de busca e indexação na Web terão mais informações sobre as páginas. Portanto, a busca poderá ser mais especializada. A popularização dos metadados na Web também facilitará a ação de agentes de software automatizados. A Web de hoje, uma vasta massa de informação não estruturada, pode no futuro se transformar em algo mais gerenciável e portanto algo ainda mais útil.

Neste trabalho, anotações foram modeladas como metadados RDF, e para isso foram estudados os três grandes componentes do RDF: o modelo de dados, a sintaxe para intercâmbio de metadados e o esquema. O modelo de dados fornece uma estrutura conceitual e abstrata para definir metadados. Já a sintaxe é necessária para a criação e intercâmbio de metadados. Os esquemas, por sua vez, fornecem informação sobre a interpretação dos statements em um modelo de dados RDF. 


\section{Capítulo 5}

\section{Serviço GroupNote: Modelagem e Implementação}

\subsection{Considerações Iniciais}

Com o intuito de prover anotações colaborativas na Web como hiperdocumentos de primeira classe na Web Semântica, de forma a ser utilizado por várias aplicações e ser extensível, um serviço aberto de anotações denominado GroupNote foi modelado e implementado neste trabalho.

Alguns dos requisitos para o serviço foram obtidos do estudo de alguns sistemas hipermídia e de anotações na Web, apresentados nos capítulos anteriores. A compilação desses requisitos, juntamente com outros requeridos de ambientes hipermídia colaborativos, são apresentados na Seção 5.2. Uma vez definidos os requisitos, foi feita a modelagem conceitual do serviço apresentada na Seção 5.3. Dada a modelagem conceitual, foi feita a modelagem RDF de anotação e de pastas de anotações apresentada na Seção 5.4. Uma API para o serviço de anotações, denominada GroupNote, foi definida e implementada, sendo apresentada na Seção 5.5. Por fim, na Seção 5.6 são apresentadas as considerações finais deste capítulo. 


\subsection{Requisitos}

A seguir é apresentado um conjunto de requisitos que nortearam a construção do serviço GroupNote. Esses requisitos foram compilados do estudo de alguns sistemas hipermídia e de anotações na Web, bem como do estudo dos requisitos demandados de ambientes hipermídia colaborativos, tais como aqueles discutidos por Halasz [Halasz, 1988] e Grønbæk e Trigg [Grønbæk and Trigg, 1999].

- Anotações como hiperdocumentos de primeira classe. Anotações estão no formato de hipertexto e são entidades com características próprias, não compartilhando da mesma definição dada à entidade documento. Assim, é possível distinguir anotações de documentos, e conseqüentemente será possível compartilhar as anotações e fazer buscas sobre atributos como autor, título e data de criação;

- Acesso às anotações pela Web. A Web é um meio de disseminação de informações;

- Disponibilização de anotações como recursos Web tradicionais, possuindo então um URI;

- Associação de metadados a anotações, através do RDF. O RDF atribui um significado bem definido a anotações, permitindo seu uso por humanos e seu processamento por software de uma maneira cooperativa;

- Definição de anotações em XML, favorecendo a interoperabilidade entre aplicações;

- Anotações individuais e de grupo. Indivíduos são capazes de ter acesso exclusivo às anotações que eles criam e de dar permissão a outros para ler ou modificar seus conteúdos;

- Organização de anotações em pastas. Pastas podem conter subpastas;

- Permissões de acesso a anotações e pastas de anotações de acordo com a categoria do usuário;

- Anotações podem anotar documentos ou existirem independentes deles. Caso anotem documentos, estes são anotados como um todo ou em porções de tamanho variável;

- Edição assíncrona do conteúdo de uma mesma anotação; 
- Notificação de eventos. É uma atividade necessária para manter os usuários conscientes das atividades dos colegas sobre os recursos compartilhados. Com isso, os usuários devem ter a facilidade de escolher os eventos sobre os quais querem ser notificados;

- Anotações podem responder anotações, como num fórum de discussão; e

- Tecnologias abertas. Facilidade na extensão do serviço de anotações e suporte à interoperabilidade entre aplicações.

\subsection{Modelagem Conceitual}

O modelo conceitual do serviço GroupNote contém as classes Annotation, Folder, User, Group e Event apresentadas na Figura 5.1 em notação UML (Unified Modeling Language) [Fowler and Scott, 2001].

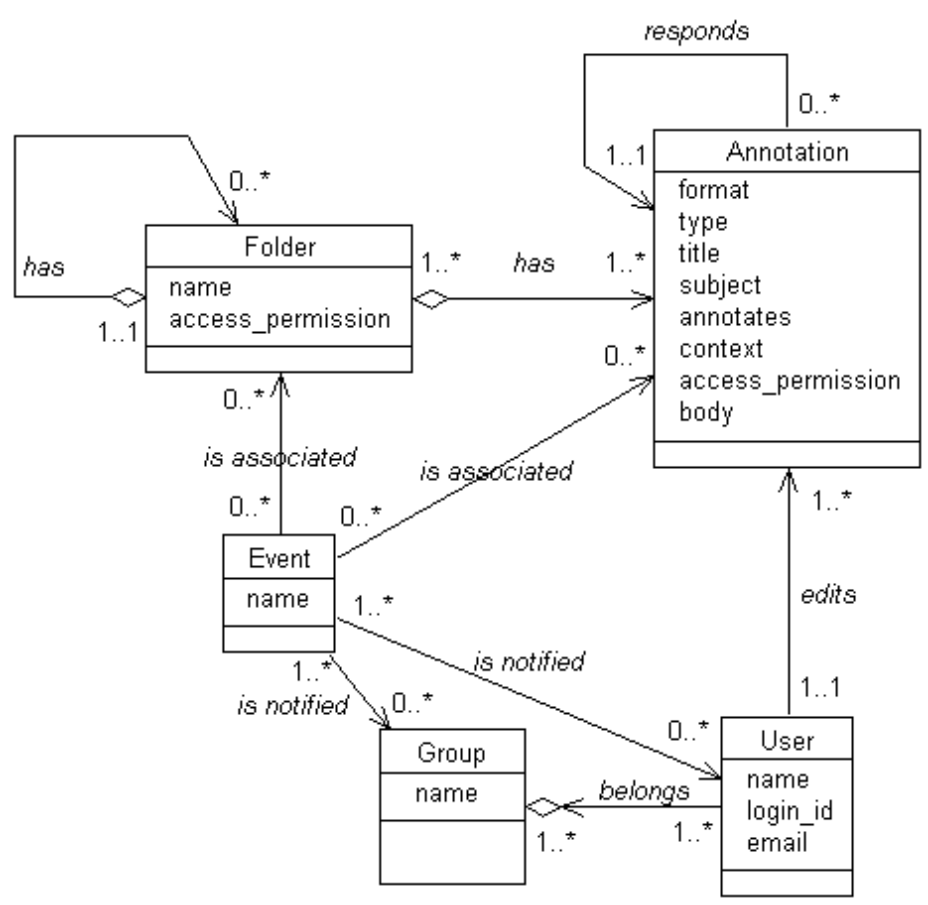

Figura 5.1: Modelo conceitual do serviço de anotações GroupNote.

A classe principal é Annotation e possui os seguintes atributos:

- Uma anotação pode estar em vários formatos (por exemplo, texto ou áudio); o formato de uma anotação é dado pelo atributo format; 
- Uma anotação pode ser de vários tipos (por exemplo, comment, question) e são especificados no atributo type;

- A uma anotação podem ser atribuídos um título e palavras-chave (mantido nos atributos title e subject);

- Uma anotação pode estar associada a um documento como um todo, a uma porção do documento, ou a um ponto do documento; o documento é representado pelo atributo annotates e a porção ou ponto pelo atributo context;

- Uma anotação guarda informação a respeito de quais permissões de acesso são dadas ao proprietário e ao grupo ao qual pertence. Essa informação é mantida pelo atributo access_permission; e

- Uma anotação possui um conteúdo, especificado no atributo body.

Uma anotação pode responder outra anotação e ser respondida por várias anotações. Esse relacionamento é representado pelo auto-relacionamento responds da classe Annotation.

O relacionamento edits entre a classe User e a classe Annotation permite o estabelecimento do proprietário da anotação. O relacionamento belongs entre a classe User e a classe Group permite o estabelecimento de qual grupo o usuário pertence.

Para modelar o fato de que as anotações são organizadas (agregadas) em pastas, existe uma outra classe importante no modelo, a classe Folder. Uma pasta também pode possuir uma agregação de subpastas, representado pelo auto-relacionamento na classe Folder. Para suportar acesso compartilhado a uma pasta, a classe Folder possui o atributo access_permission.

Para modelar a notificação de eventos sobre as pastas e anotações compartilhadas pelos usuários, foi criada a classe Event, que se relaciona com as classes User, Group, Annotation e Folder. Com isso, o usuário pode cadastrar a sua intenção de ser notificado (ou de notificar seu grupo) quando os recursos compartilhados (anotações e pastas) sofrem modificações.

Para suportar anotações individuais e de grupo, quatro categorias de usuários e dois tipos de permissão de acesso foram definidos. Essas categorias de usuários e tipos de permissão de acesso são semelhantes aos do UNIX.

- As categorias de usuários são: owner, group, other e guest. A categoria owner é relacionada ao usuário que criou a anotação; a categoria group é relacionada 
ao grupo ao qual o usuário pertence; a categoria other é relacionada aos demais usuários registrados no servidor; por último, a categoria guest é relacionada a usuários que não estão cadastrados no sistema.

- As permissões de acesso definidas são:

- Para as categorias owner, group e other: leitura e escrita, ambos para anotação e pasta.

- Para a categoria guest, somente permissão de leitura.

\subsection{Modelagem de Anotações e Pastas de Anotações na Web Semântica}

Nesta seção é apresentada a modelagem RDF dos recursos anotação e pasta de anotações em termos de modelagem de dados RDF e sintaxe XML. Uma porção do esquema RDF de anotações e pastas também é apresentada.

\subsubsection{Modelagem RDF de Anotação}

Enquanto a classe Annotation na Figura 5.1 modela uma anotação como um objeto, o grafo (modelo de dados RDF) apresentado na Figura 5.2 modela uma anotação como um recurso Web. Os atributos modelados na classe Annotation na Figura 5.1 são modelados como propriedades na Figura 5.2 (adicionalmente com outras propriedades).

Neste trabalho foram reutilizadas definições de conjuntos de elementos (namespaces) do Dublin Core [Initiative, 1999] (indicado por "dc:") e do Annotea [W3C, 2001b] (indicado por "a:"). Um conjunto de elementos próprios indicados por "an:" [Izeki, 2001] foi definido neste trabalho.

Especificamente no modelo de dados apresentado na Figura 5.2:

- A propriedade RDF rdf : type foi utilizada para indicar que uma instância do recurso possui todas as características que são esperadas de um membro da classe; em outras palavras, que uma instância é do tipo anotação. 


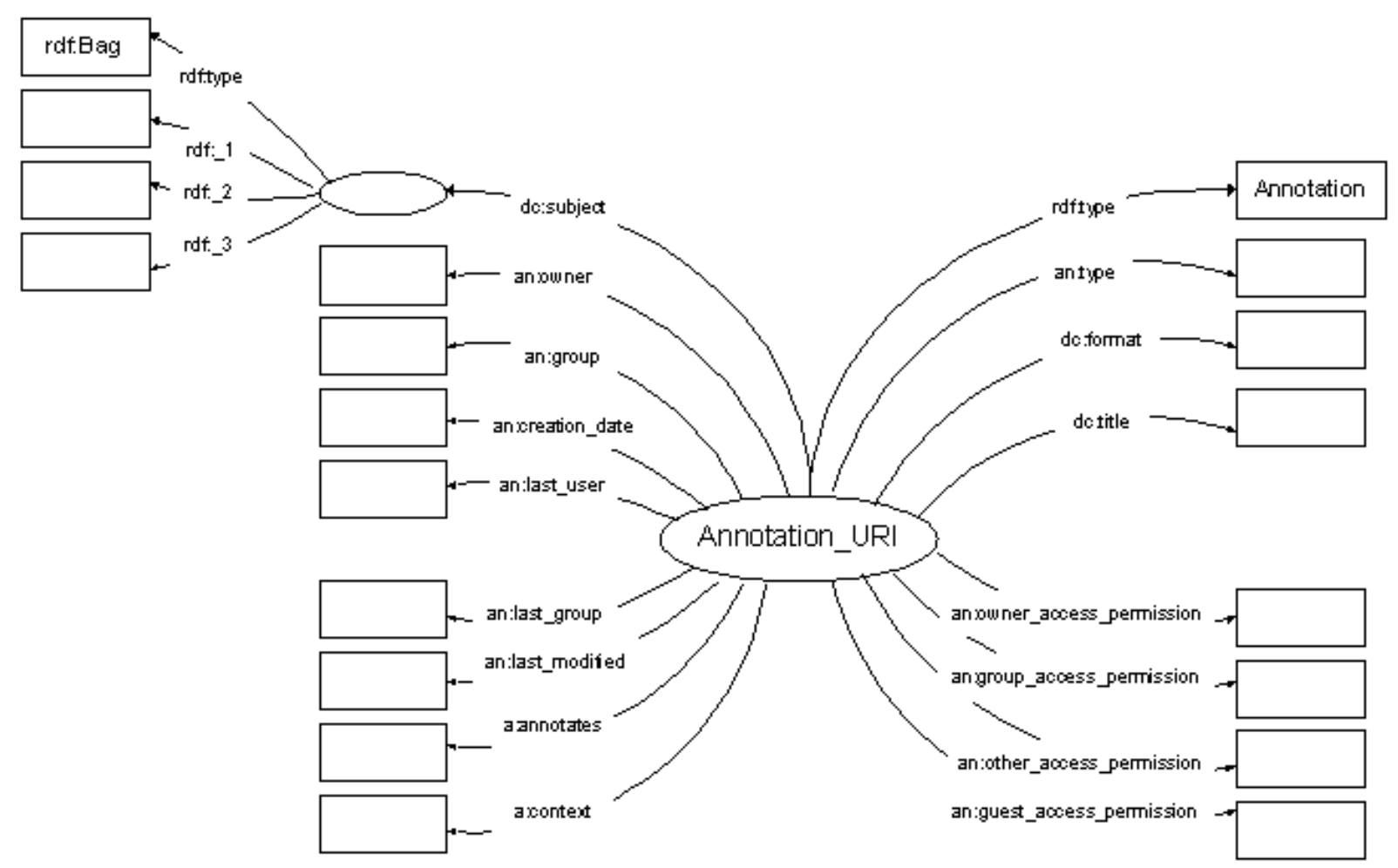

Figura 5.2: Modelo de dados RDF de um recurso Anotação.

- A propriedade an:type foi definida para especificar o tipo da anotação, ou seja, para especificar se a anotação é do tipo example, explanation ou outro.

- As propriedades dc:title e dc:format do Dublin Core foram reusadas para especificar o título e o formato da anotação (por exemplo, "text/html").

- A propriedade dc:subject do Dublin Core foi reusada para associar palavras-chave a uma anotação. Entretanto, especializou-se a definição original usando o tipo rdf:Bag para conter até 3 strings representadas em rdf :_1, rdf :_2 e rdf :_3.

- As propriedades an:owner, an:group, an:last_user, an:last_group, an:creation_date e an:last_modified foram definidas para especificar, respectivamente, a identidade do proprietário da anotação e do grupo ao qual pertence, a identidade do usuário e do grupo que realizou a última modificação, e as datas de criação e de última modificação da anotação.

- A propriedade dc:annotates do Annotea foi reusada para representar a identificação do documento sendo anotado (se existir).

- A propriedade dc:context do Annotea foi reusada para especificar um ponto ou uma região dentro do documento sendo anotado (se existir). 
- As propriedades an:owner_access_permission, an:group_access_permission, an: other_access_permission e an: guest_access_permission foram definidas para especificar as permissões de acesso para owner, group, other e guest, respectivamente.

Como um exemplo de quais informações estão disponíveis como metadados para uma anotação, um documento XML correspondente ao modelo de dados RDF da Figura 5.2 é apresentado na Figura 5.3.

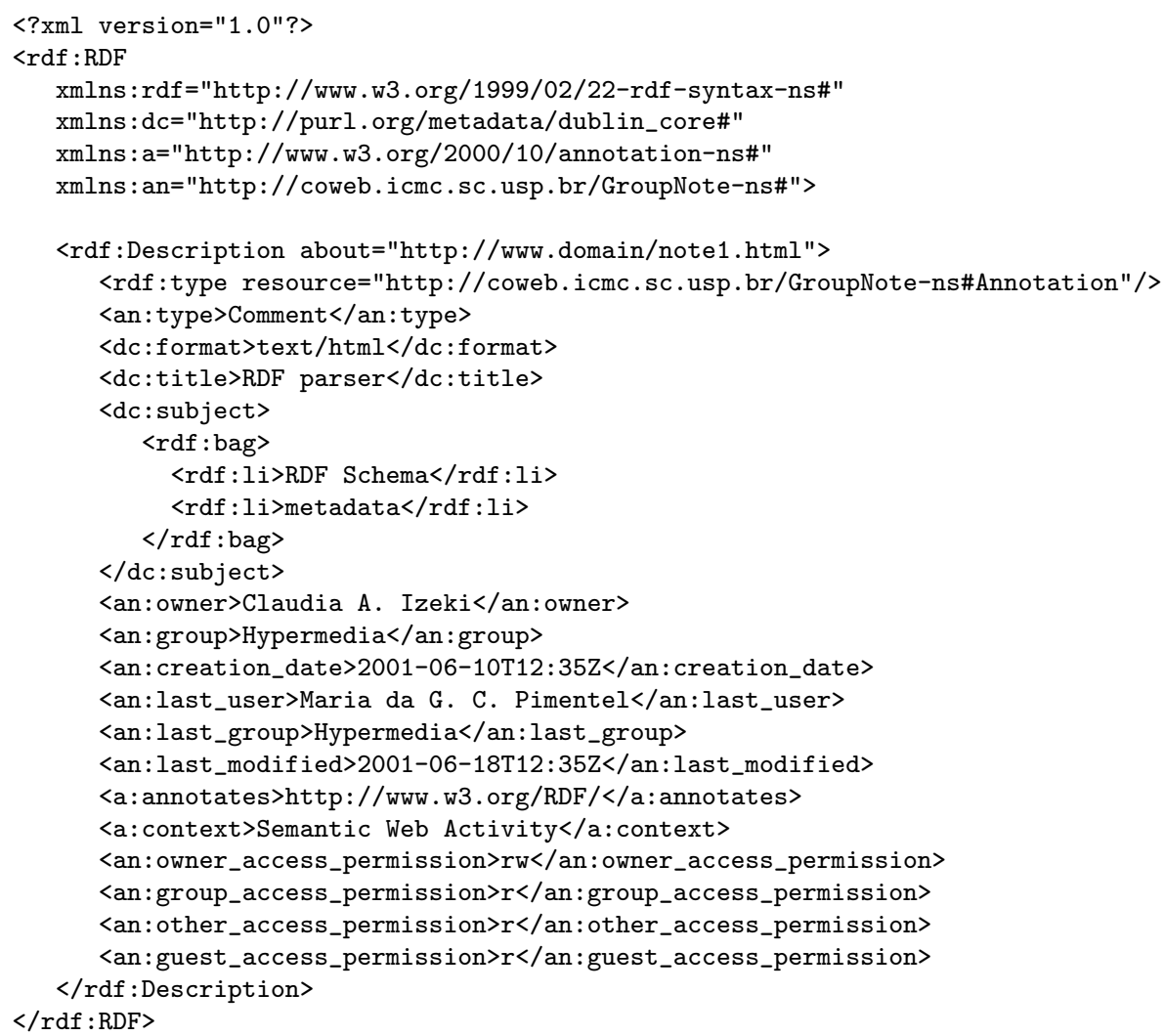

Figura 5.3: Uma instância RDF de um recurso Anotação.

\subsubsection{Modelagem RDF de Pasta de Anotações}

O processo de modelagem de dados RDF de pastas é semelhante ao de anotação. O modelo de dados RDF apresentado na Figura 5.4 define uma pasta como um recurso Web. Os atributos modelados na classe Folder na Figura 5.1 são modelados como propriedades na Figura 5.4 (adicionalmente com outras propriedades). 


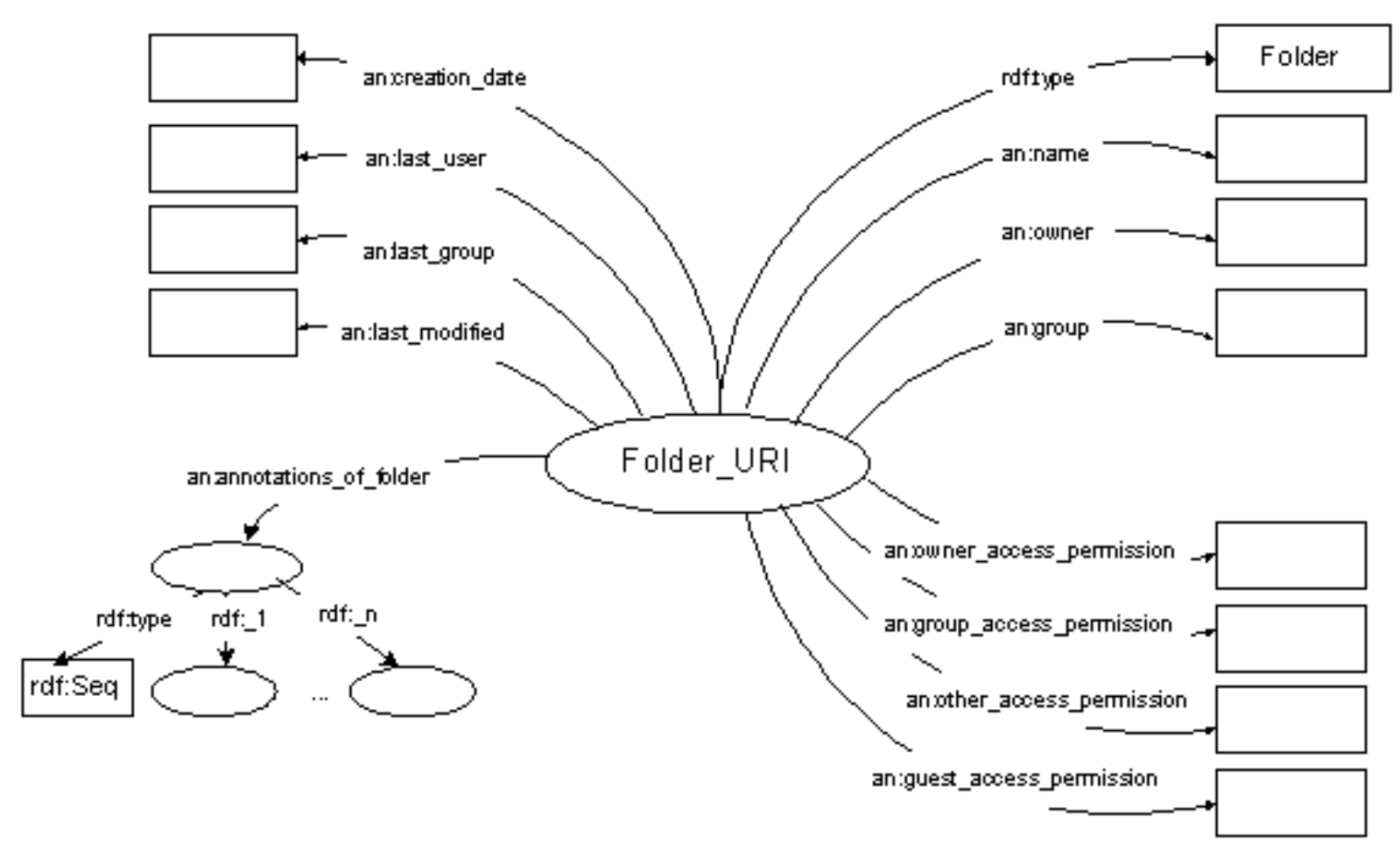

Figura 5.4: Modelo de dados RDF de um recurso Pasta.

No modelo de dados de uma pasta foram utilizados os mesmos conjuntos de elementos do modelo de dados da anotação: Dublin Core (indicado por "dc:"), Annotea (indicado por "a:") e GroupNote (indicado por "an:").

O modelo de dados de pasta é semelhante ao de anotação, possuindo propriedades comuns, como: usuário e grupo criador, data de criação e alteração, usuário e grupo que efetuaram a última modificação e as permissões de acesso. O nome e anotações de uma pasta (indicados por an:name e an:annotations_of_folder) são propriedades que diferem do modelo de dados da anotação. Cada círculo pontilhado na Figura 5.4 representa um modelo de dados de uma anotação que compõe a pasta, como aquele apresentado na Figura 5.2.

Como um exemplo de quais informações estão disponíveis como metadados para uma pasta, um documento XML correspondente ao modelo de dados RDF da Figura 5.4 é apresentado na Figura 5.5. 


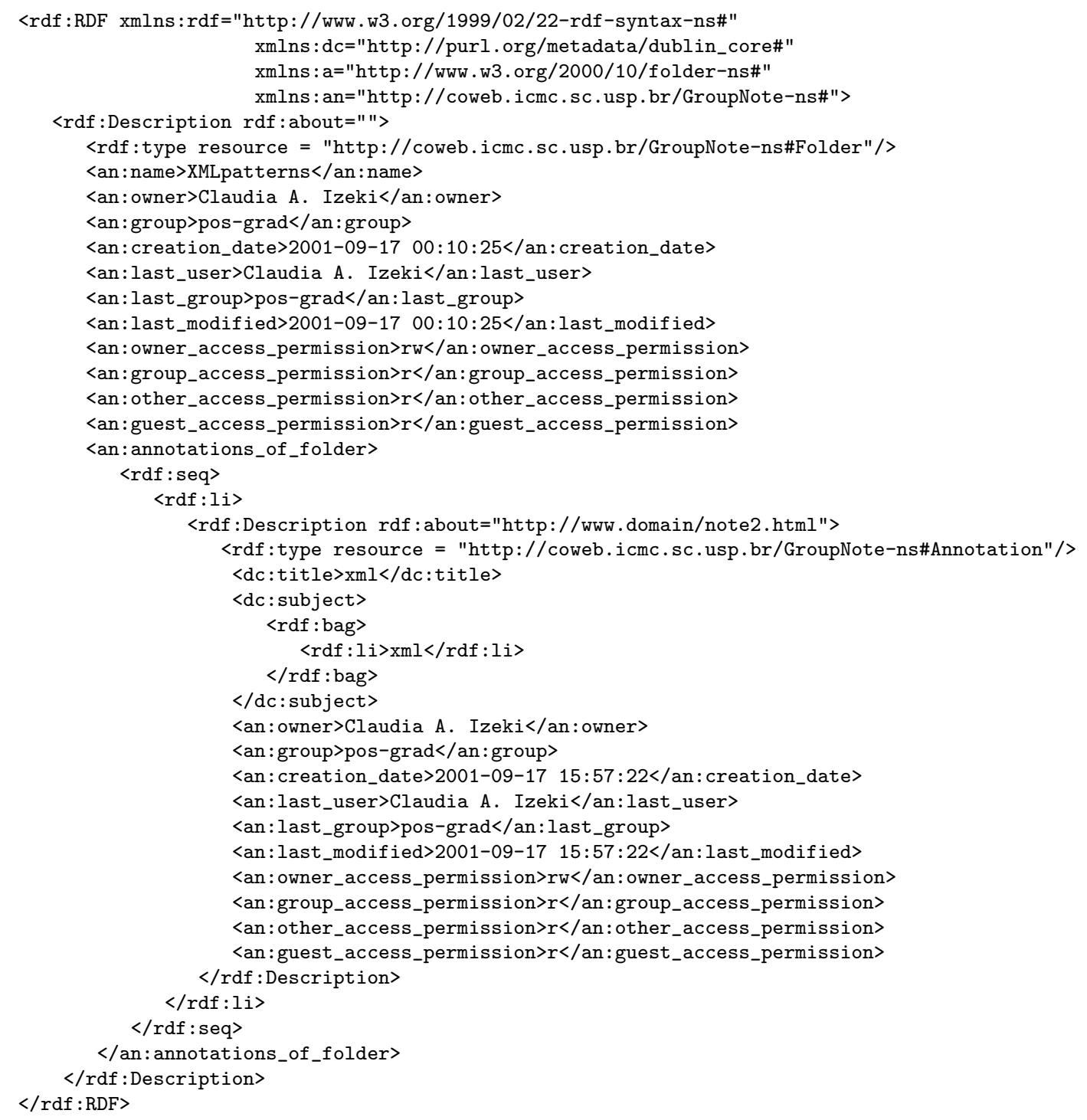

Figura 5.5: Uma instância RDF de um recurso Pasta.

\subsubsection{Uma Porção do Esquema RDF dos Recursos Anotação e Pasta de Anotações}

Com o intuito de mostrar como o esquema RDF é utilizado para declarar as propriedades de anotações e pastas e definir os relacionamentos entre as propriedades e os recursos, é apresentada apenas uma parte do esquema RDF, mostrada na Figura 5.6. O esquema RDF completo dos recursos anotação e pasta está disponível em http://coweb.icmc.sc.usp.br/GroupNote-ns.

Na Figura 5.6 são apresentadas as definições da classe Annotation e da propriedade 
owner. A classe Annotation, representada por rdfs:Class, é definida pelo recurso indicado entre aspas após o elemento resource em rdfs:isDefinedBy. Esse recurso, na realidade, é o próprio documento que define o esquema RDF do GroupNote. O idioma da documentação é suportada pela utilização do elemento xml:lang, que neste caso é o inglês, segundo a notação xml:lang='en'. A descrição da classe Annotation compreensível por humanos: "The target type of a annotation resource" é denotada através da propriedade rdfs:comment. A propriedade rdfs:label é também uma documentação, utilizada para rotular o nome do recurso, no caso Annotation.

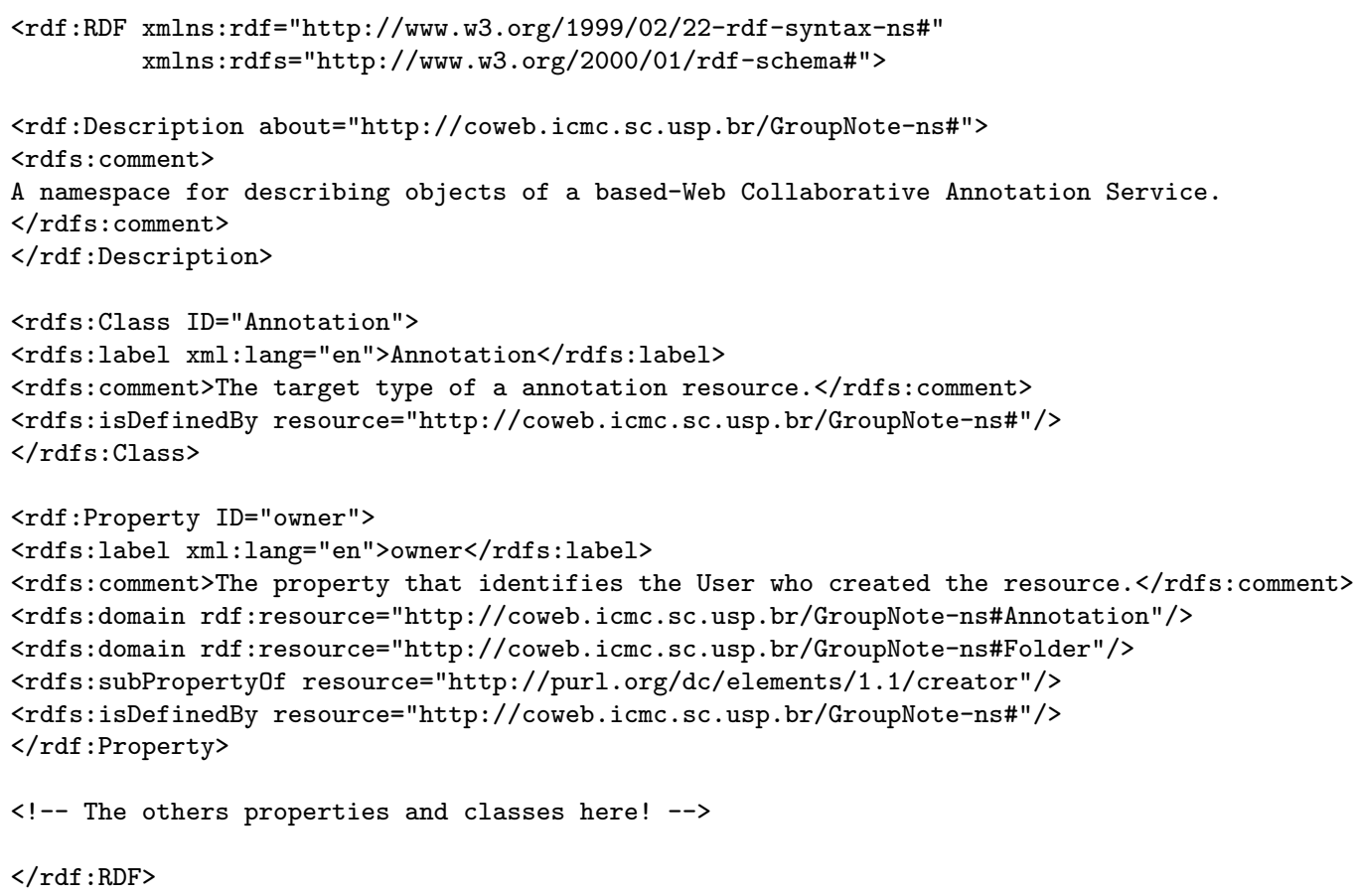

Figura 5.6: Uma porção do esquema RDF dos recursos Anotação e Pasta

A propriedade owner possui rótulo com o mesmo nome e também possui um comentário compreensível por humanos. A propriedade rdfs:domain é utilizada para indicar as classes que as propriedades podem ser usadas, no caso as classes Annotation e Folder. Com isso, definiu-se um relacionamento de classe (recurso) e propriedade. Já a propriedade creator é uma subpropriedade (indicada por rdfs:subPropertyOf) da propriedade creator definida pelo Dublin Core, ou seja, creator é uma especialização do seu correspondente no Dublin Core. Finalmente, da mesma forma que a classe Annotation, a propriedade owner é definida pelo recurso que é o próprio documento que define o esquema RDF. 


\subsection{API GroupNote}

O serviço de anotações GroupNote foi implementado como uma Application Programming Interface (API), o que permite que desenvolvedores de aplicações possam reusar e combinar as operações em seus próprios blocos de construção. O serviço foi implementado utilizando um servidor Web Apache (versão 1.3.19) estendido com um processador PHP (versão 4.0.4) e uma base de dados MySQL (versão 3.23.36) no sistema operacional Linux (Distribuição REDHAT).

A API GroupNote foi implementada como quatro conjuntos complementares: API Annotation, API Folder, API User and Group e API Event.

- A API Annotation define métodos relacionados com: (a) a criação e remoção de anotações, (b) a alteração dos atributos das anotações, (c) o controle de acesso dos usuários às anotações, (d) o bloqueio e o desbloqueio de anotações, (e) a obtenção das propriedades das anotações e (f) a geração de metadados RDF e de dados XML correspondentes às anotações. Os métodos de controle de acesso garantem que as anotações sejam acessadas somente por usuários que possuam as permissões apropriadas. Os métodos de controle de bloqueio garantem que um usuário tenha permissão de escrita sobre uma anotação por um intervalo de tempo. Esse controle é implementado utilizando o bloqueio de escrita exclusiva do WebDAV [Whitehead and Wiggins, 1998, Goland et al., 1999], apresentado no Apêndice A com as características de implementação. Os métodos para a geração de metadados RDF de anotações fornecem mecanismos para aplicações acessarem os metadados das anotações sem acessarem os seus conteúdos.

- A API Folder define métodos relacionados com: (a) a criação e a remoção de pastas, (b) a alteração dos atributos das pastas (como, por exemplo, nome e permissão de acesso), (c) o controle de acesso dos usuários às pastas, (d) a manipulação de anotações em pastas (como, por exemplo, copiar/mover anotações de uma pasta para outra), (e) a obtenção das propriedades das pastas e (f) a geração de metadados RDF correspondentes às pastas e seus conteúdos.

- A API User and Group define métodos relacionados com: (a) a criação, a remoção e a busca de usuários, (b) a alteração e a busca de atributos de usuários, (c) a criação, a remoção e a busca de grupos, (d) a alteração e a busca dos atributos dos grupos, (e) a inserção de usuários em grupos, (f) a remoção de usuários de grupos e (g) a autenticação de usuários. 
- A API Event define métodos relacionados com: (a) a criação e a remoção de eventos, (b) a alteração dos nomes dos eventos, (c) o cadastro das intenções dos usuários em serem notificados quando determinados eventos ocorrerem no sistema e (d) a geração da notificação de eventos aos usuários através de correio eletrônico.

A documentação da API GroupNote pode ser encontrada em http://coweb.icmc.sc.usp.br/incaserve.

\subsection{Considerações Finais}

O serviço de anotações GroupNote foi modelado e implementado para prover anotações colaborativas na Web como hiperdocumentos de primeira classe. Para alcançar esse objetivo foram investigados, na literatura e na Web em geral, o estado da arte das anotações, resultando na compilação de vários requisitos. Uma vez levantado os requisitos foi realizada a modelagem conceitual do serviço. A partir daí foram feitas as modelagens RDF dos recursos anotação e pasta e a API GroupNote foi definida e implementada.

De modo geral, o serviço GroupNote dá suporte:

- Ao controle de acesso às anotações e pastas através das permissões de acesso semelhantes às do UNIX;

- Ao controle de concorrência da edição de uma mesma anotação, através do bloqueio de escrita exclusiva do WebDAV;

- À notificação, por correio eletrônico, de eventos ocorridos sobre os recursos compartilhados (anotação e pasta). É permitido aos projetistas da aplicação cadastrarem novos eventos;

- À disponibilização de metadados de anotações e pastas, através da sintaxe XML do $\mathrm{RDF}$; e

- À disponibilização da anotação (conteúdo e metadados) em formato XML.

Para validar o serviço GroupNote, foi realizado um estudo de caso com a implementação de uma aplicação denominada WebNote, apresentada no próximo capítulo. 


\section{Capítulo 6}

\section{WebNote: Um Estudo de Caso}

\subsection{Considerações Iniciais}

A metáfora básica do WebNote são pastas nas quais as anotações podem ser manipuladas colaborativamente. O WebNote permite que um usuário tenha seu próprio repositório de anotações na Web independentemente de qualquer documento sendo anotado.

No WebNote, usuários podem criar pastas e anotações e permitir acesso a outros membros do sistema para a leitura e escrita do conteúdo das mesmas. Para utilizar o sistema, o usuário deve estar registrado no sistema e ser membro de pelo menos um grupo.

O WebNote foi implementado utilizando um servidor Web Apache (versão 1.3.19) estendido com um processador PHP (versão 4.0.4) no sistema operacional Linux (Distribuição REDHAT).

Este capítulo descreve a aplicação WebNote como um estudo de caso do serviço GroupNote, apresentado no capítulo anterior. Na Seção 6.2 são apresentadas as funcionalidades da API GroupNote que dão suporte à aplicação. Na Seção 6.3 é apresentada uma visão geral do WebNote. Nas demais seções são descritas as funcionalidades do WebNote, tais como: hierarquia de pastas e suas operações (Seção 6.4), operações sobre anotações (Seção 6.5) e mudança de grupo de usuários (Seção 6.6), mostrando como elas são suportadas pela API. Por último, na Seção 6.7 são apresentadas as considerações finais deste capítulo. 


\subsection{Suporte da API GroupNote}

O WebNote foi implementado utilizando-se os quatro conjuntos de APIs do GroupNote: "Annotation", "Folder", "User and Group" e "Event".

A API Folder dá suporte às seguintes funcionalidades do WebNote:

- Criação de pastas em qualquer nível de profundidade, formando uma hierarquia de pastas;

- Visualização de pastas como uma árvore (hierarquia) de pastas;

- Remoção de pastas;

- Alteração dos nomes de pastas;

- Mudança de permissão de acesso de pastas;

- Manipulação de anotações em pastas (por exemplo, mover/copiar uma anotação de uma pasta para outra);

- Apresentação de propriedades (metadados) de pastas;

- Apresentação de anotações contidas em uma pasta; e

- Verificação de permissões de leitura/escrita do usuário sobre as pastas. Isso é importante na habilitação/desabilitação de certas operações. Por exemplo, se um usuário não possui permissão de escrita para uma pasta, isso significa que ele não pode criar anotações nessa pasta. Com isso, a operação de criar anotação pode ser desabilitada.

A API Annotation dá suporte às seguintes funcionalidades do WebNote:

- Criação e remoção de anotações;

- Alteração dos atributos de anotações;

- Mudança de permissão de acesso de anotações;

- Apresentação das propriedades de anotações;

- Bloqueio e desbloqueio de anotações para resolver o problema da concorrência quando dois ou mais usuários desejam editar a mesma anotação; e 
- Visualização de anotação como documentos XHTML com metadados. O documento XHTML é gerado pelo cliente através do processamento de documentos documentos XML e stylesheets XSLT. The API Annotation fornece documentos XML e RDF com dados e metadados da anotação, respectivamente.

A API "User and Group" dá suporte às seguintes funcionalidades do WebNote:

- Manipulação de usuário por um administrador: criar, apagar e buscar usuários e alterar atributos de usuários;

- Manipulação de grupo por um administrador: criar, apagar, renomear e buscar grupos;

- Manipulação de usuário em grupo: inserir/apagar usuários em/de grupos;

- Mudança de grupo;

- Obtenção dos atributos de usuários e grupos; e

- Autenticação de usuários.

Finalmente, a API "Event" dá suporte às seguintes funcionalidades do WebNote:

- Cadastro das intenções dos usuários em serem notificados quando determinados eventos ocorrerem no sistema;

- Geração da notificação de eventos aos usuários através de correio eletrônico; e

- Cadastro de eventos por projetistas da aplicação.

\subsection{Visão Geral do WebNote}

A interface do WebNote, apresentada na Figura 6.1 é composta por três frames, onde:

- O frame superior mostra o nome e o grupo do usuário, bem como as seguintes operações: busca de anotações, mudança de grupo, ajuda e saída do sistema. A apresentação do nome e grupo do usuário é suportada pelas funções 
get_user_attributes e get_group_name, respectivamente. Para verificar se a âncora "change group" deve ser habilitada, a função user_belongs_to_several_groups é utilizada;

- O frame esquerdo mostra a hierarquia de pastas de anotações. Ao lado de cada nome de pasta existem dois ícones: o primeiro ícone é utilizado para acessar as operações sobre a pasta atual e o segundo ícone é utilizado para mostrar as propriedades da pasta atual e para mudar suas permissões de acesso; e

- O frame direito possui finalidades, como: apresentar as anotações contidas na pasta atual, mostrar as operações sobre as pastas, exibir os formulários de criação, de alteração e de busca de anotações e exibir as anotações resultantes de buscas.

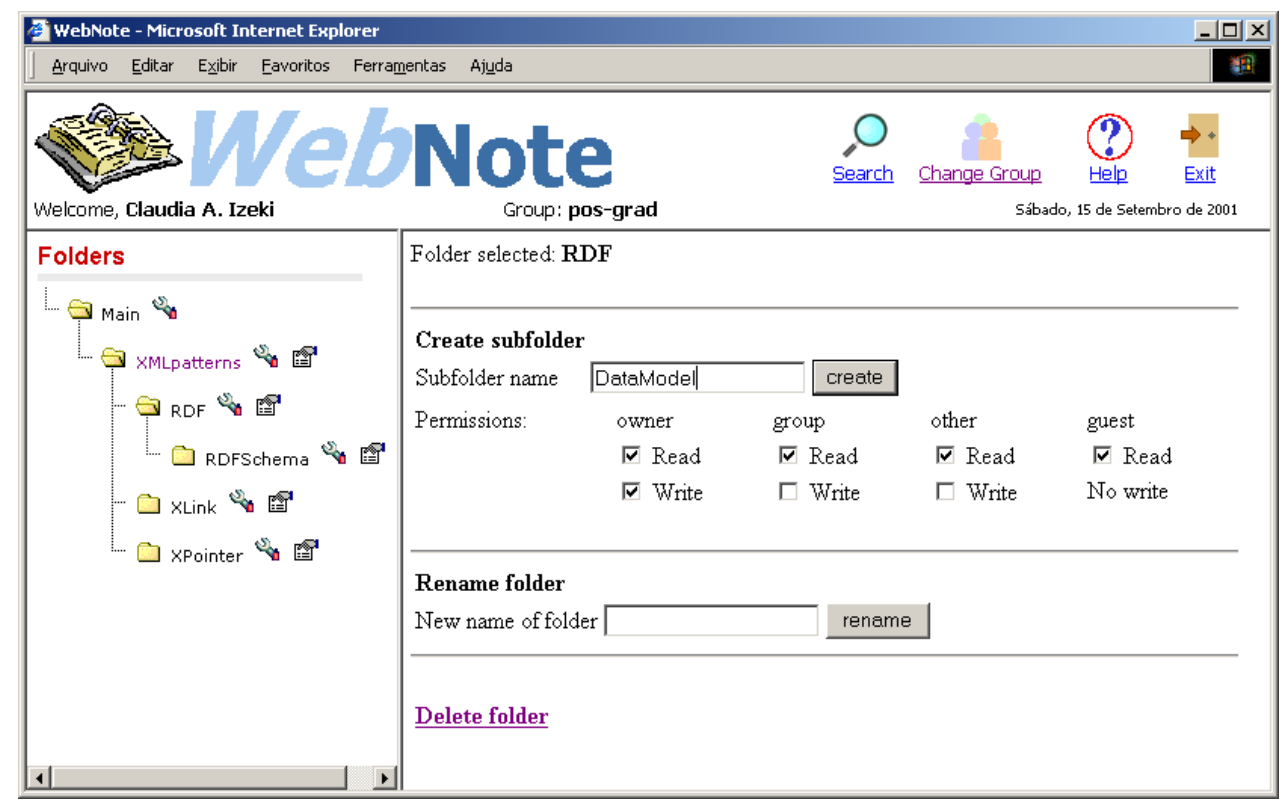

Figura 6.1: A interface do WebNote é composta por três frames.

\subsection{Pastas - Hierarquia e Operações}

No WebNote, pastas podem ser criadas em vários níveis, formando uma hierarquia de pastas. Essa decisão foi tomada para permitir que os usuários organizem melhor suas anotações. Para a interface do WebNote suportar essa funcionalidade foram usadas as seguintes funções da API: (a) get_folder_level_zero para obter todas as pastas do nível zero do usuário atual, (b) get_folder_name para obter o nome da pasta e (c) get_folder_children para obter as pastas-filho da pasta atual. O uso dessas três 
funções gera uma árvore de pastas como aquela apresentada na Figura 6.2. O usuário pode abrir ou fechar uma pasta simplesmente clicando sobre o ícone em formato de pasta localizado à frente do nome da pasta.

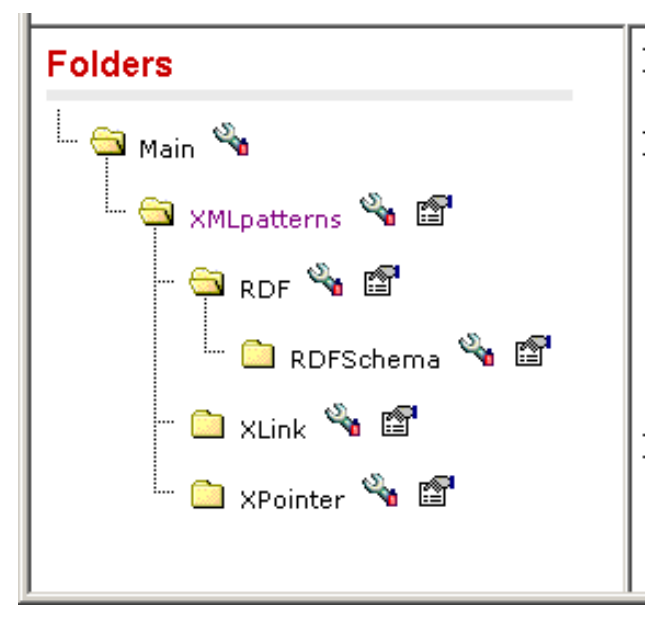

Figura 6.2: Apresentação das pastas em hierarquia no WebNote.

Do lado direito de cada nome de pasta existem dois ícones:

- O primeiro ícone, no formato de uma ferramenta, representa as operações sobre a pasta atual: criar subpasta, renomear e apagar pasta. Essas operações são suportadas pelas seguintes funções da API, respectivamente: create_folder, set_folder_name e delete_folder. Todas essas funções verificam se o usuário possui permissão para realizar a operação escolhida. Quando o usuário clicar sobre o ícone em formato de ferramenta, as operações sobre a pasta atual são apresentadas no frame direito da Figura 6.1.

- O segundo ícone permite a visualização das propriedades da pasta (por exemplo, data de criação, usuário e grupo proprietário, etc.) e a alteração de suas permissões de acesso. Para apresentar as propriedades da pasta é utilizada a função get_folder_rdf que retorna os metadados da pasta. Para alterar as permissões de acesso da pasta é utilizada a função set_folder_accesspermission. Somente o proprietário da anotação pode alterar as permissões de acesso . O usuário guest não possui permissão de escrita no sistema. Quando o usuário clicar sobre o ícone de propriedades, uma janela com as propriedades da pasta atual é aberta, como mostrada na Figura 6.3.

Para apresentar as anotações contidas em uma pasta, o usuário deve selecionar o nome da pasta no frame esquerdo. As anotações são apresentadas no frame direito, como 


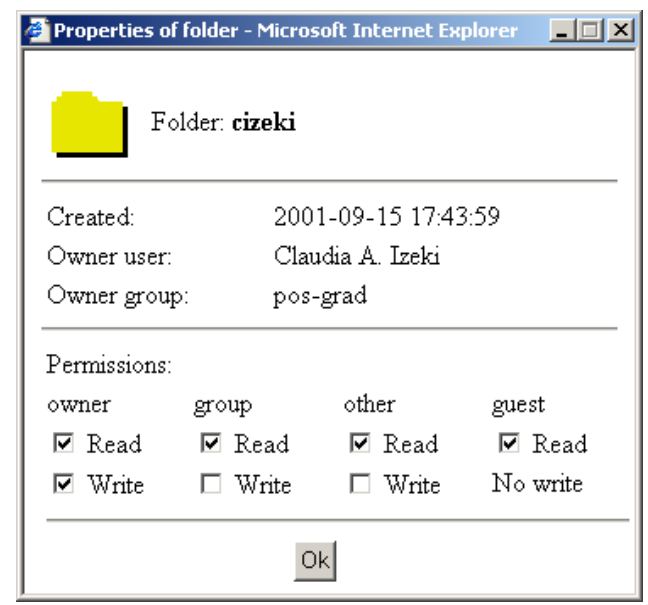

Figura 6.3: Janela com as propriedades da pasta atual no WebNote.

mostrado na Figura 6.4. Para verificar a habilitação ou não das operações de criar, apagar, mover e copiar anotações, a função test_user_can_write_folder é usada. Para mostrar as propriedades de cada anotação é usada a função get_folder_rdf que retorna os metadados de todas as anotações da pasta atual.

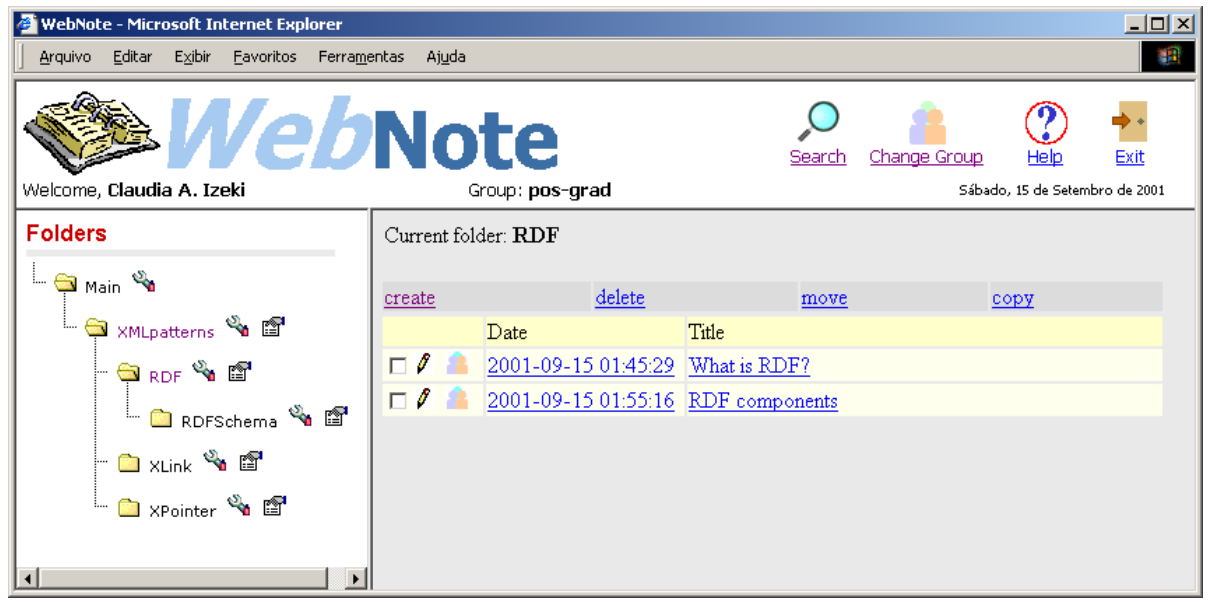

Figura 6.4: Apresentação de alguns metadados das anotações da pasta atual no WebNote.

\subsection{Operações sobre Anotações}

No WebNote, as operações disponíveis para as anotações são:

- Criar anotação: as funções create_annotation, get_annotation_xml e get_annotation_ rdf são usadas. Quando um usuário submete os dados do formulário, como aquele apresentado na Figura 6.5, é chamada a função 
create_annotation que cria uma anotação caso o usuário tenha as devidas permissões. Por conseguinte, do lado do cliente, são invocadas as funções get_annotation_xml e get_annotation_ rdf, respectivamente, para a criação do arquivo XML da anotação e do arquivo stylesheet XSLT. O arquivo stylesheet XSLT representa uma transformação do arquivo XML para o HTML. Entre as tags HEAD do HTML é inserido o RDF da anotação. O parser XSLT XT de James Clark ${ }^{1}$ gera o documento XHTML da anotação através do processamento dos arquivos XML e XSLT criados. Essa transformação é feita no lado do cliente. Um exemplo de um documento XHTML gerado por esse processamento é apresentado na Figura 6.6. As permissões de acesso padrão são: leitura e escrita para owner e leitura para group, other e guest. O corpo da anotação pode ser formatado usando tags como <b> (bold) e <i> (italic). O usuário pode optar em ser notificado por correio eletrônico quando alguém editar sua anotação. Essa funcionalidade é suportada pela função create_user_subscribing_to_notification_of_event.

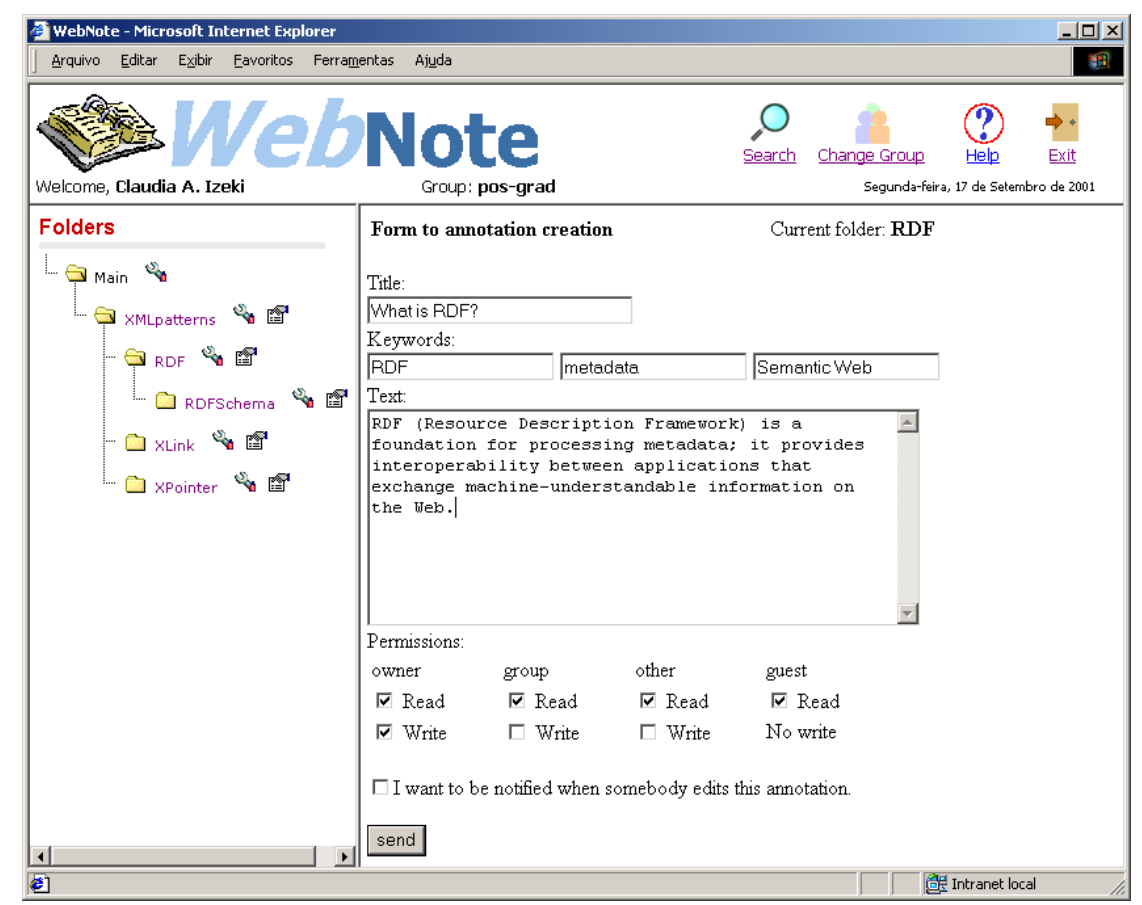

Figura 6.5: Interface de criação de anotação no WebNote.

- Apagar anotação: a função delete_annotation é usada. O usuário possui a possibilidade de apagar várias anotações de uma vez.

- Mover anotações para pasta(s): a função move_annotation_for_folder é usada. Essa função verifica se o usuário possui permissão de escrita para as pastas origem

\footnotetext{
${ }^{1}$ parser XT de James Clark - http://www.jclark.com
} 


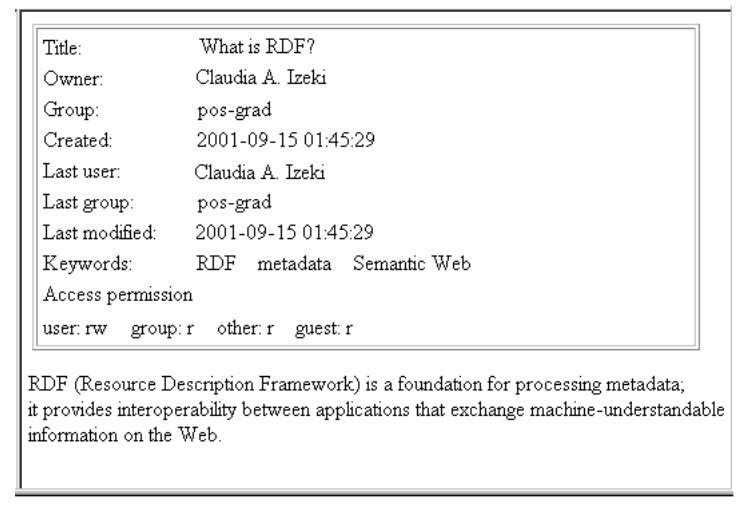

Figura 6.6: Exemplo de um documento XHTML de uma anotação.

e destino. O usuário possui a possibilidade de mover várias anotações de uma vez.

- Copiar anotações para pasta(s): a função copy_annotation_for_folder é usada. Essa função verifica se o usuário possui permissão de escrita para a pasta destino. O usuário possui a possibilidade de copiar várias anotações de uma vez.

- Editar anotação: a função locks_annotation é usada quando o usuário mostra a sua intenção em editar a anotação. O ícone em formato de lápis representa a âncora para editar a anotação. A função set_annotation_attributes é usada para alterar os atributos da anotação e desbloqueá-la.

- Mudar as permissões de acesso da anotação: a função set_annotation_accesspermission é usada. Somente o proprietário da anotação pode alterar as permissões de acesso.

- Apresentação do conteúdo da anotação com os seus metadados: a função test_user_can_read_annotation é usada para verificar se o usuário possui permissão de leitura para a anotação, que é apresentada diretamente de sua URL.

- Busca de anotações: a função get_annotations é usada. Essa função verifica se o usuário possui permissão de leitura para a pasta que possui a anotação. O usuário pode procurar anotações em cinco categorias: "Nas minhas anotações deste grupo", "Em todas as minhas anotações", "Em todas as anotações deste grupo", "Em todas as anotações dos grupos aos quais pertenço" e "Em todas as anotações do sistema WebNote". O usuário pode procurar anotações por palavras-chave, título e/ou por conteúdo. A interface de busca de anotações é apresentada no frame direito (Figura 6.7) após o usuário ter selecionado a opção "Search" do frame superior. 


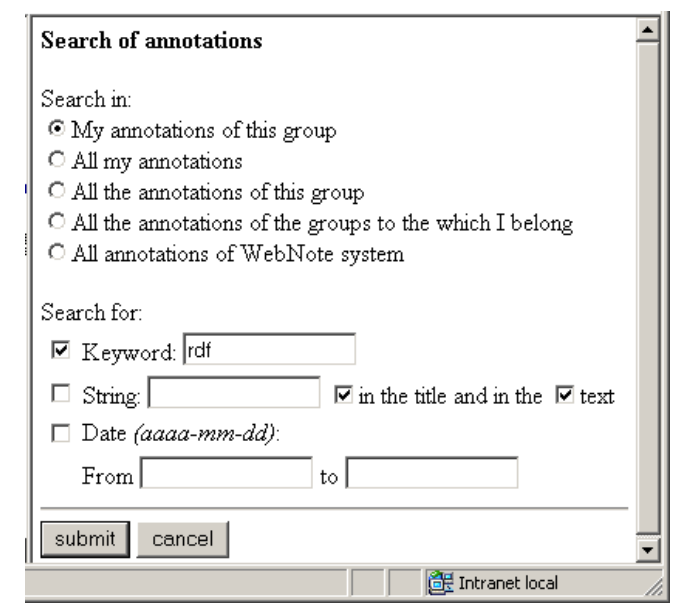

Figura 6.7: Interface de busca de anotações no WebNote.

\subsection{Mudança de Grupo}

O usuário pode mudar para qualquer grupo ao qual pertence selecionando a opção "Change Group" no frame superior. Uma janela é aberta, como mostrada na Figura 6.8. A função get_user_groups é usada para obter todos os grupos aos quais o usuário está cadastrado.

\begin{tabular}{|c|c|}
\hline Change group - Mi & Internet Expl... \\
\hline \multirow{2}{*}{$\begin{array}{l}\text { Current group: } \\
\text { Change to group: }\end{array}$} & pos-grad \\
\hline & hipermidia $=$ \\
\hline \multicolumn{2}{|c|}{ change } \\
\hline
\end{tabular}

Figura 6.8: Janela para mudança de grupo no WebNote.

\subsection{Considerações Finais}

O WebNote utilizou grande parte das funcionalidades do serviço de anotações GroupNote para implementar uma aplicação de anotações individuais e de grupo, na qual cada usuário possui seu próprio repositório de anotações na Web independentemente de qualquer documento sendo anotado.

Com o WebNote foram testadas as principais funções da API GroupNote relacionadas:

- Ao controle de acesso às anotações e pastas através das permissões de acesso semelhantes às do UNIX; 
- Ao controle de concorrência através do bloqueio e desbloqueio de anotações utilizando o lock de escrita exclusiva do WebDAV;

- À notificação de eventos por correio eletrônico. Por enquanto a único evento cadastrado é quando alguém editar uma determinada anotação. Entretanto, a estrutura da API em relação à notificação foi implementada de maneira a ser extensível a outros eventos;

- À utilização do XML e RDF da anotação, juntamente com um processador XSLT, para gerar o documento XHTML da anotação; e

- À utilização do RDF da pasta para obter as propriedades das pastas e das anotações que compõem a pasta.

Algumas melhorias no WebNote podem ser realizadas, como por exemplo: apresentar as pastas dos demais usuários do mesmo grupo juntamente no mesmo frame no qual as pastas do usuário atual são apresentadas e dar a possibilidade do usuário criar seus próprios tipos de anotação (por exemplo, "example", "question", etc.) para melhor identificar suas anotações. 


\section{Capítulo 7}

\section{Conclusões e Trabalhos Futuros}

Este trabalho apresentou o GroupNote, um serviço aberto de suporte a anotações colaborativas como hiperdocumentos de primeira classe na Web Semântica. O GroupNote foi apresentado em termos de: (a) levantamento de requisitos, (b) modelagem conceitual, (c) modelagem dos metadados de anotações e pastas, (d) funcionalidades oferecidas pela API implementada e (e) validação da API através da implementação da aplicação WebNote.

De modo geral, o serviço GroupNote dá suporte:

- Ao controle de acesso às anotações e pastas através das permissões de acesso semelhantes às do UNIX;

- Ao controle de concorrência da edição de uma mesma anotação, através do bloqueio de escrita exclusiva do WebDAV;

- À notificação, por correio eletrônico, de eventos ocorridos sobre os recursos compartilhados (anotação e pasta). É permitido aos projetistas da aplicação cadastrarem novos eventos;

- À disponibilização de metadados de anotações e pastas, através da sintaxe XML do RDF; e

- À disponibilização da anotação (conteúdo e metadados) em formato XML para, por exemplo, em conjunto com o RDF da anotação, gerar um documento XHTML semântico de anotação. 


\subsection{Contribuições}

As contribuições do presente trabalho são:

- Os requisitos levantados para a construção de um serviço colaborativo de anotações como hiperdocumentos de primeira classe na Web Semântica;

- A produção de modelagem RDF de anotações com permissões de acesso;

- A disponibilização pública do conjunto de operações que integram a API do serviço de anotações GroupNote;

- A possibilidade de integração do serviço GroupNote com outras aplicações; e

- A implementação do WebNote, que é uma aplicação que suporta anotações individuais e de grupo, na qual cada usuário possui seu próprio repositório de anotações na Web independentemente de qualquer documento sendo anotado.

\subsection{Trabalhos Futuros}

Como trabalhos futuros pode-se citar:

- Extensão do serviço GroupNote para suportar versionamento de anotações através do uso da API denominada Version Web [Soares et al., 2000];

- Investigação do suporte à troca de informação em um ambiente distribuído através do protocolo de comunicação XML, denominado SOAP (Simple Object Access Protocol)[Gudgin et al., 2001];

- Integração do serviço GroupNote com outras aplicações, como por exemplo as aplicações do contexto do Projeto InCA-SERVE [Pimentel and Abowd, 1999]:

- CoTeia [Arruda and Pimentel, 2001], um ambiente de edição colaborativa assíncrona de páginas Web utilizada no ICMC-USP desde o segundo semestre de 2001 ;

- eMeet/Serve [Eleutério and Pimentel, 2001], uma infra-estrutura de suporte a reuniões distribuídas em grupo; 
- ChatServer [Cattelan, 2001], um serviço de conferência síncrona baseado em troca de mensagens textuais, que suporta características especiais como conversão XML de sessões de chat;

- Integração da aplicação WebNote ao WLS [Bulcão, 2001], um serviço aberto de ligações hipermídia para Web;

- Investigação do uso do WebDAV para suportar bloqueio de escrita compartilhada;

- Produção de nota didática sobre RDF e Web Semântica de modo geral.

\subsection{Considerações Finais}

O suporte a anotações é um tema que tem sido explorado em todas as gerações de sistemas hipermídia, e mais atualmente em aplicações na Web. Particularmente no contexto de anotações na Web, a demanda atual é por um serviço aberto e extensível, baseado nas especificações XML e RDF, como aquele provido pelo Annotea, mas que também atenda aos requisitos tradicionais de serviços de anotação. A API GroupNote permitiu a implementação da aplicação WebNote com características de suporte a grupos em termos de controle de acesso, controle de concorrência de edição e notificação de eventos. Uma extensão imediata ao GroupNote é o suporte ao versionamento de anotações. 


\section{Referências Bibliográficas}

[Abowd, 1999] Abowd, G. D. (1999). Classroom 2000: An Experiment with the Instrumentation of a Living Educational Environment. IBM Systems Journal, 38(4):508-530.

[Adriano et al., 1999] Adriano, C. M., Raposo, A. B., and Ricarte, I. L. M. (1999). Implementação de Metáforas de Anotação e Paradigmas de Interação em Ambientes Educacionais. In SBIE'99, pages 399-401, Curitiba, PR.

[Akscyn et al., 1987] Akscyn, R., McCracken, D., and Yoder, E. (1987). KMS: A Distributed Hypermedia System for Managing Knowledge in Organizations. Hypertext'87, pages $1-20$.

[Amazon, 2001] Amazon (2001). Amazon. On-line in World Wide Web. http://www. amazon.com.

[Andrews et al., 1995] Andrews, K., Kappe, F., and Maurer, H. (1995). HyperG and Harmony: Towards the Next Generation of Networked Information Technology. CHI'95. Denver.

[Arruda and Pimentel, 2001] Arruda, C. R. E. and Pimentel, M. G. C. (2001). Projeto e Implementação de um Sistema Colaborativo de Edição. Revista Eletrônica de Iniciação Científica da Sociedade Brasileira de Computação, 2. A ser publicado em Novembro/2001.

[Berners-Lee et al., 2001] Berners-Lee, T., H., J., and Lassila, O. (2001). The Semantic Web. On-line in World Wide Web. http://www.scientificamerican.com/2001/ 0501issue/0501berners-lee.html.

[Brown, 1987] Brown, P. J. (1987). Turning Ideas into Products: The Guide System. Hypertext'87, pages 33-40. 
[Bulcão, 2001] Bulcão, R. F. (2001). WLS: Um Serviço Aberto de Ligações Hipermídia para Web baseado em XML. Dissertação de mestrado, Instituto de Ciências Matemáticas e de Computação, São Carlos, São Paulo. Setembro/2001.

[Bush, 1945] Bush, V. (1945). As We May Think. The Atlantic Montly. pp. 101-108.

[Cattelan, 2001] Cattelan, R. G. (2001). Chatserver 2.0. Relatório de pesquisa do $1^{o}$ semestre de 2001, Instituto de Ciências Matemáticas e de Computação, São Carlos, São Paulo. Julho/2001.

[Cultura, 2001] Cultura, L. (2001). Livraria Cultura. On-line in World Wide Web. http: //www.livcultura.com.br.

[Davis and Huttenlocher, 1995] Davis, J. R. and Huttenlocher, D. P. (1995). Shared Annotation for Cooperative Learning. In CSCL'95 Proceedings, pages 84-88, Bloomington.

[Davis et al., 1998] Davis, R. C., Lin, J., Brotherton, J. A., Landay, J. A., Price, M. N., and Schilit, B. N. (1998). A Framework for Sharing Handwritten Notes. UIST'98, pages 119-120.

[Eleutério and Pimentel, 2001] Eleutério, P. M. S. and Pimentel, M. G. C. (2001). Geração Sob Demanda de Hiperdocumentos Multimídia a partir de Informação Capturada em Reuniões Distribuídas. Anais do I Workshop de Teses e Dissertações do SBMídia'2001. A ser publicado em Outubro/2001.

[Engelbart, 1984] Engelbart, D. C. (1984). Authorship Provisions in Augment. In Proceedings of 28th IEEE International Conference, pages 465-472, San Francisco, CA, USA.

[Fowler and Scott, 2001] Fowler, M. and Scott, K. (2001). UML Distilled: Applying the Standard Object Modeling Language, volume 1. Addison-Wesley. 208 pp.

[Goland et al., 1999] Goland, Y., Whitehead, E., Faizi, A., Carter, S., and Jensen, D. (1999). HTTP Extensions for Distributed Authoring - Web DAV. Internet Proposed Standard RFC 2518.

[Grønbæk and Trigg, 1999] Grønbæk, K. and Trigg, R. H. (1999). From Web to Workplace: Designing Open Hypermedia Systems, volume 1. MIT Press. 386 pp.

[Gudgin et al., 2001] Gudgin, M., Hadley, M., Moreau, J. J., and Nielsen, H. F. (2001). Simple Object Acess Protocol (SOAP) version 1.2 - W3C Working Draft. On-line in World Wide Web. http://www.w3.org/TR/soap12/. 
[Guzdial, 1998] Guzdial, M. (1998). Collaborative Websites Supporting Open Authoring. Submitted Journal of the Learning Sciences.

[Halasz, 1988] Halasz, F. G. (1988). Reflections on NoteCards: Seven Issues for the Next Generation of Hypermedia Systems. Communications of the ACM, 31(7):836-852.

[Halasz et al., 1987] Halasz, F. G., Moran, T. P., and Trigg, R. H. (1987). Notecards in a Nutshell. In Proceedings of the ACM CHI + GI Conference, pages 45-52, Toronto.

[IJHCS, 2001] IJHCS (2001). International Journal Human-Computer Studies. On-line in World Wide Web. http://ijhcs.open.ac.uk/.

[Initiative, 1999] Initiative, D. C. M. (1999). Dublin Core Metadata Element Set, Version 1.1: Reference Description. On-line in World Wide Web. http://dublincore.org/ documents/dces.

[Izeki, 2001] Izeki, C. A. (2001). Groupnote RDF Schema. On-line in World Wide Web. http://coweb.icmc.sc.usp.br/GroupNote-ns.

[Kahan et al., 2001] Kahan, J., Koivunen, M., Prud'Hommeaux, E., and Swick, R. R. (2001). Annotea: An Open RDF Infrastructure for Shared Web Annotations. In Proceedings of the WWW10 International Conference, Hong Kong.

[Lucena and Fuks, 1998] Lucena, C. and Fuks, H. (1998). AulaNet - An Environment for the Development and Maintenance of Courses on the Web. In Proceedings ICEE'98International Conference On Engineering Educational, Rio de Janeiro - RJ.

[Maurer, 1996] Maurer, H. (1996). HyperWave. Addison-Wesley-Longman, London.

[mozdev.org, 2001] mozdev.org (2001). Anozzila - Annotea on Mozilla. On-line in World Wide Web. http://annozilla.mozdev.org/.

[Nelson, 1992] Nelson, T. H. (1992). Literary Machines. Mindful Press.

[Pimentel and Abowd, 1999] Pimentel, M. G. C. and Abowd, G. (1999). Development and Understanding of Automated Capture Environments to Support Long-Term Use. Projeto de cooperação internacional ProTeM-CC-CNPq/Brasil e NSF/EUA, 3 anos a partir de Ago/2000. Processo 480113-9.

[Pimentel et al., 2001] Pimentel, M. G. C., Kerimbaev, Y. I. B., Abowd, G. D., and Guzdial, M. (2001). Supporting Long-term Educational Activities Through Dynamic Web Interfaces. Interacting With Computers Journal, 13:353-374. 
[Röscheisen et al., 1995] Röscheisen, M., Mogensen, C., and Winograd, T. (1995). Shared Web Annotations as a Platform for Third-Party Value-Added Information Providers: Architecture, Protocols, and Usage Examples. On-line in World Wide Web. http: //www-diglib.stanford.edu/diglib/pub/reports/commentor.html.

[Schilit et al., 1998] Schilit, B. N., Golovchinsky, G., and Price, M. N. (1998). Beyond Paper: Supporting Active Reading with Free Form Digital Ink Annotations. CHI'98, pages 249-256. Los Angeles, CA, USA.

[Soares et al., 2000] Soares, M. D., Fortes, R. P. M., and Moreira, D. A. (2000). VersionWeb: A Tool for Helping Web Pages Version Control. International Conference on Internet Multimedia Systems and Applications, pages 275-280.

[Submarino, 2001] Submarino (2001). Submarino. On-line in World Wide Web. http: //www. submarino.com.br.

[T. Catlin, 1989] T. Catlin, P. Bush, N. Y. (1989). InterNote: Extending a Hypermedia Framework to Support Annotative Collaboration. In Hypertext'89 Proceedings, pages $365-378$.

[Trigg and Irish, 1987] Trigg, R. H. and Irish, P. M. (1987). Hypertext Habitats: Experiences of Writers in Notecards. Hypertext'87, pages 89-108.

[Truong and Abowd, 1999] Truong, K. N. and Abowd, G. (1999). StuPad: Integrating Student Notes with Class Lectures. Extended Abstracts of CHI'99, pages 208-209.

[W3C, 1999a] W3C (1999a). Resource Description Framework (RDF) Model and Syntax Specification. On-line in World Wide Web. http://www.w3.org/TR/REC-rdf-syntax.

[W3C, 1999b] W3C (1999b). Semantic Web Activity: Resource Description Framework (RDF). On-line in World Wide Web. http://www.w3.org/RDF.

[W3C, 2000] W3C (2000). Resource Description Framework (RDF) Schema Specification 1.0 - W3C Candidate Recommendation. On-line in World Wide Web. http://www. w3. org/TR/2000/CR-rdf-schema-20000327/.

[W3C, 2001a] W3C (2001a). Amaya Home Page - W3C's Editor/Browser. On-line in World Wide Web. http://www.w3.org/Amaya.

[W3C, 2001b] W3C (2001b). Annotea RDF Schema. On-line in World Wide Web. http: //www.w3.org/2000/10/annotation-ns\#. 
[W3C, 2001c] W3C (2001c). Semantic Web Activity. On-line in World Wide Web. http: //www.w3.org/2001/sw.

[W3C, 2001d] W3C (2001d). XML Linking Language (XLink). On-line in World Wide Web. http://www.w3.org/TR/xlink.

[W3C, 2001e] W3C (2001e). XML Pointer Language (XPointer). On-line in World Wide Web. http://www.w3.org/TR/xptr.

[WebCT, 2001] WebCT (2001). World Wide Web Course Tools. On-line in World Wide Web. http://www. webct.com/webct.

[Weiser, 1993] Weiser, M. (1993). Some Computer Science Issues in Ubiquitous Computing. Communications of the ACM, 6(7):75-84.

[Whitehead and Wiggins, 1998] Whitehead, E. J. and Wiggins, M. (1998). WEBDAV: IETF Standard for Collaborative Authoring on the Web. IEEE Internet Computing, pages 34-40.

[Wojahn et al., 1998] Wojahn, P. G., Neuwirth, C. M., and Morris, R. (1998). Effects of Interfaces for Annotation on Communication in a Collaborative Task. CHI'98, pages 456-463.

[Yankelovich et al., 1988] Yankelovich, N., Haan, B. J., Meyrowitz, N. K., and Drucker, S. M. (1988). Intermedia: The Concept and the Construction of a Seamless Information Environment. IEEE Computer.

[Yee, 1999] Yee, K. P. (1999). The CritLink Mediator. On-line in World Wide Web. http://crit.org/http://crit.org/critlink.html.

[Yoder et al., 1989] Yoder, E., Akscyn, R., and McCracken, D. (1989). Collaboration in KMS, A Shared Hypermedia System. In CHI'89 Proceedings, pages 37-42. 


\section{Apêndice A}

\section{WebDAV - suporte ao controle de concorrência}

Para implementar o controle de concorrência quando vários usuários desejam editar a mesma anotação, foi utilizado o bloqueio de escrita exclusiva do WebDAV ( Web-based Distributed Authoring and Versioning) [Whitehead and Wiggins, 1998, Goland et al., 1999].

WebDAV é um conjunto de extensões para o protocolo HTTP que permite que os usuários editem e gerenciem arquivos colaborativa e assincronamente sobre servidores Web remotos. WebDAV está sendo desenvolvido pelo grupo de trabalho WebDAV do IETF (Internet Engineering Task Force). Esse grupo de trabalho surgiu em 1995 numa conferência em Boston, como um encontro informal de pessoas interessadas em autoria remota na Web. Em 1997 foi formalmente consolidada como um grupo de trabalho do IETF. O W3C e os fabricantes influentes como Microsoft, Nestcape, Xerox, IBM, e Novell têm ajudado no desenvolvimento do WebDAV. O objetivo é fazer da Web um ambiente colaborativo de fato.

Para suportar o bloqueio do WebDAV, foi instalado um módulo do WebDAV no servidor Apache, o mod_dav. A configuração básica no arquivo httpd.conf para o funcionamento do WebDAV é apresentada a seguir.

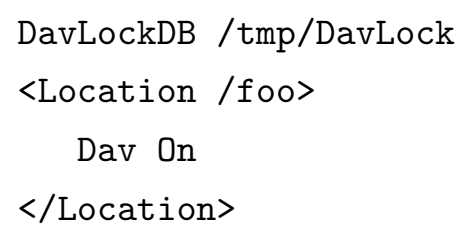


A diretiva Dav On habilita os métodos HTTP WebDAV para um dado diretório, no caso /foo. A diretiva DavLockDB especifica o caminho completo para a base de dados de bloqueios, no caso /tmp/DavLock. O utilitário lockview pode ser utilizado para mostrar todos os bloqueios sobre a base de dados. A seguir são apresentados exemplos de mensagens HTTP WebDAV para bloqueio e desbloqueio de recursos Web, no caso os arquivos XHTML das anotações.

A mensagem HTTP WebDAV para bloquear o recurso http://coweb.icmc.sc.usp.br/ webnote/50annotation.html com tempo máximo de bloqueio de 1200 segundos é apresentada a seguir.

LOCK http://coweb.icmc.sc.usp.br/webnote/50annotation.html HTTP/1.1

Host: coweb.icmc.sc.usp.br

Timeout: Second-1200

Content-Type: text/xml; charset="utf-8"

Content-Length: 163

Respostas do servidor indicando que a operação de bloqueio foi sucesso ou que o recurso já está bloqueado são mostradas a seguir.

O trecho HTTP/1.1 200 OK indica que o bloqueio foi realizado com sucesso. A cadeia de caracteres após Lock-Token é o código de bloqueio que deve ser armazenado para desbloquear o recurso anotação. No trecho XML, o elemento locktype indica o tipo do bloqueio, que neste caso é o de escrita. O elemento lockscope indica o escopo do bloqueio, que é o exclusivo.

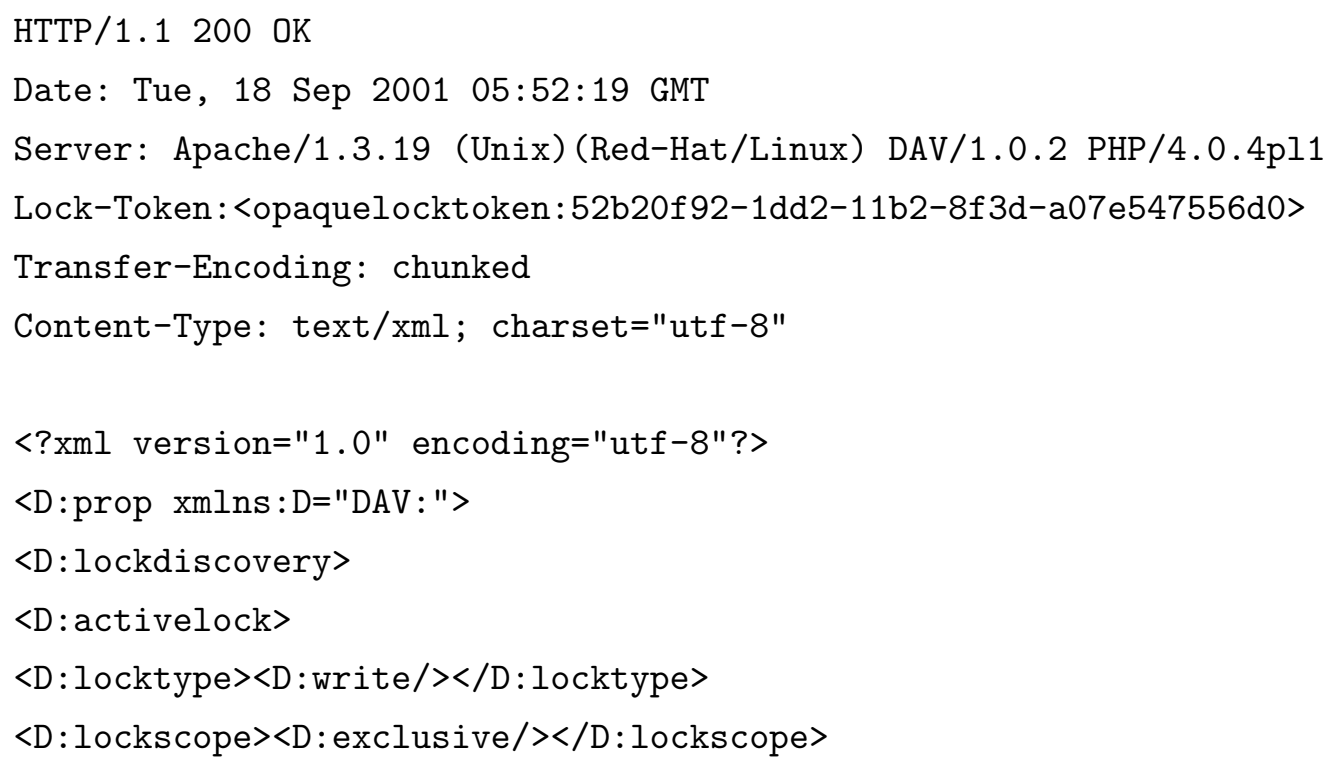




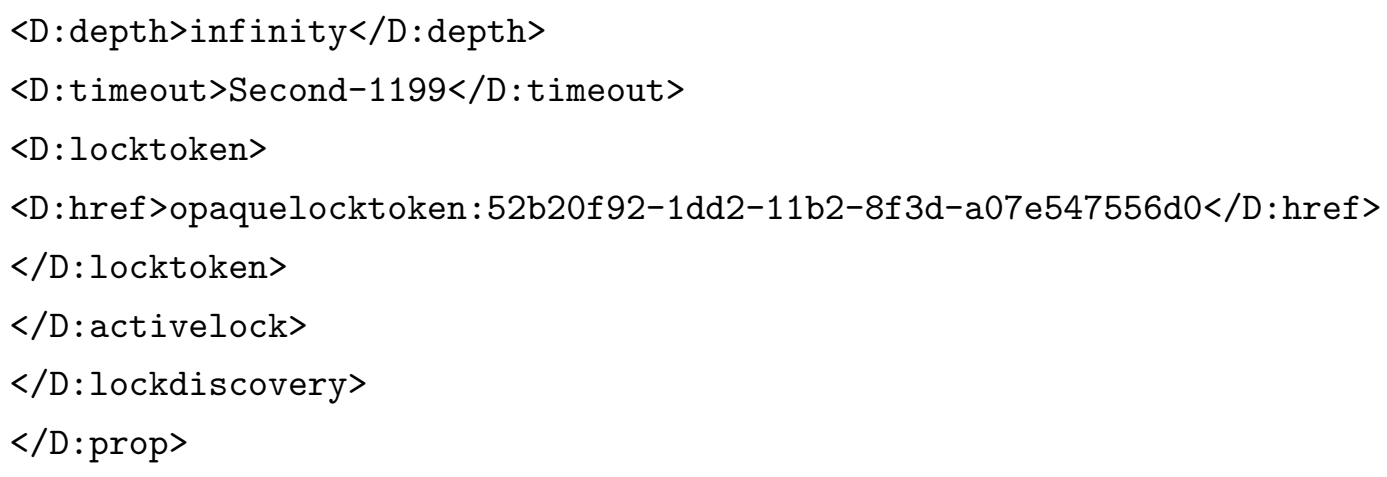

A mensagem de que o recurso está bloqueado é apresentada a seguir. O trecho HTTP/1.1 423 Locked indica que o recurso já está bloqueado.

HTTP/1.1 423 Locked

Date: Tue, 18 Sep 2001 05:54:28 GMT

Server: Apache/1.3.19 (Unix)(Red-Hat/Linux) DAV/1.0.2 PHP/4.0.4pl1

Transfer-Encoding: chunked

Content-Type: text/html; charset=iso-8859-1

Para desbloquear o recurso, deve-se enviar uma mensagem HTTP WebDAV com o código de bloqueio retornado pelo servidor e o caminho do endereço do recurso, como mostrado a seguir.

UNLOCK /webnote/annotations/50annotation.html HTTP/1.1

Host: coweb.icmc.sc.usp.br

Lock-Token:<opaquelocktoken:52b20f92-1dd2-11b2-8f3d-a07e547556d0>

A mensagem de que o recurso foi desbloqueado é apresentada a seguir. O trecho HTTP/1.1 204 No Content indica que o recurso foi desbloqueado.

HTTP/1.1 204 No Content

Date: Tue, 18 Sep 2001 06:47:03 GMT

Server: Apache/1.3.19 (Unix)(Red-Hat/Linux) DAV/1.0.2 PHP/4.0.4pl1

Content-Type: text/plain 